\title{
تحولات مفهوم الإنسان في فلسفة الحداثة وفلسفة ما بعد الحداثة من مأزق التمان إنسان التأليه إلى مأزق إنسان التشويه
}

\section{مصطفى كيحل"}

$$
\begin{aligned}
& \text { الملخص } \\
& \text { يعالج هذا البحث إشكالية التحولات التي تكتنف مفهوم الإنسان، لا سيما في عصر الحداثة، وعصر ما بعد }
\end{aligned}
$$

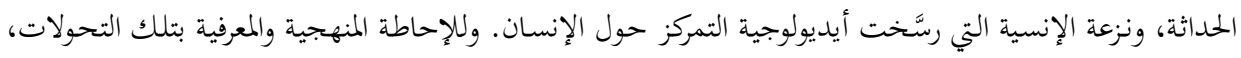

$$
\begin{aligned}
& \text { فقد تتبَّعنا مفهوم الأنسنة ومضامينه الفلسفية لتحديد أهم مستوياته الدلالية في بُعْدها الديني، والسياسي، والثقائي. وتمَّة }
\end{aligned}
$$

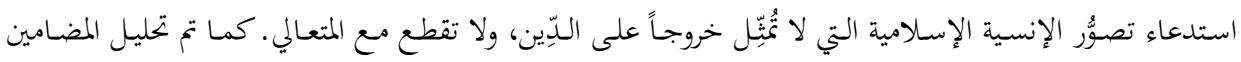

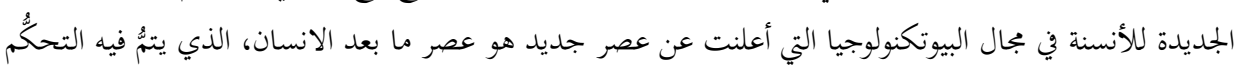

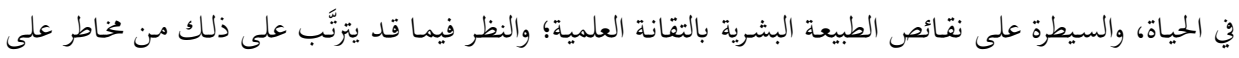

$$
\begin{aligned}
& \text { الطبيعة الإنسانية. } \\
& \text { الكلمات المفتاحية: الأنسنة، الحماثة، ما بعد الحداثة، ما بعد الإنسان، البيوتكنولوجيا، التقنوعلمي. }
\end{aligned}
$$

\section{Transformations of the Concept of Man in the Philosophy of Modernism and Postmodernism :A Dilemma from Apotheosis to Distortion.}

\section{Mostafa Kihal}

\begin{abstract}
This paper deals with the problem of the transformations that surround the concept of Man, especially in the age of modernity, postmodern, and humanism that established the ideology of human centeredness. To understand the methodology and knowledge of these transformations, we have followed the concept of humanism and its philosophical implications to determine the most important semantic levels in its religious, political, and cultural dimension. This work has called for the concept of Islamic humanism, which does not depart from religion, and does not cut off with transcendence. It also employed an analysis of the new implications of humanism in the field of biotechnology, which proclaimed a new era of post-human age in which life and defects of human nature are controlled, through scientific implications, and consider the consequent risks that may affect human nature.
\end{abstract}

Keywords: Humanism, Modernism, Postmodernism, Beyond Man, Biotechnology Techno-Science.

* دكتوراه في الفلسفة، جامعة قسنطينة، الجزائر، أستاذ فلسفة التأويل والفلسفة التطبيقية في جامعة عنابة، الجزائر. البريد

kihalmostafa@gmail.com : الإلكتروني

تم تسلم البحث بتاريخ 2018/2/10م، وقُبل للنشر بتاريخ 2018/9/3م. 


\section{مقلدمة:}

يستند تحقيب العصور التاريخي في مسيرة الحضارات إلى التحقيب المعرفي، الذي يقوم

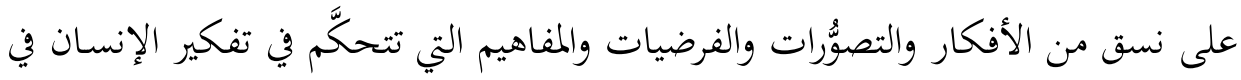

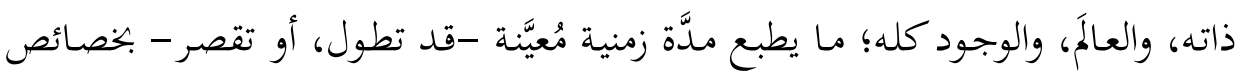

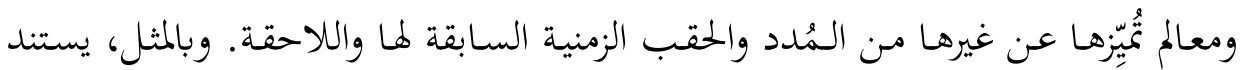

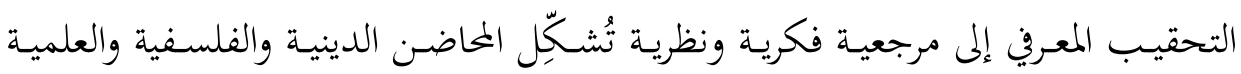

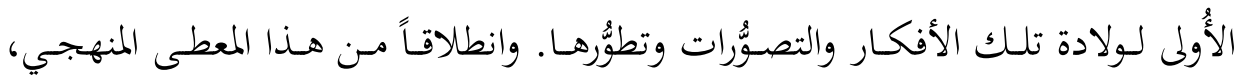

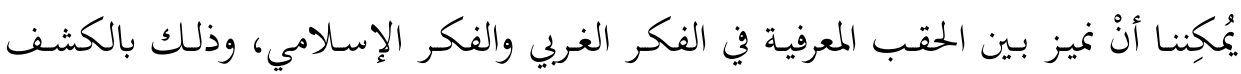

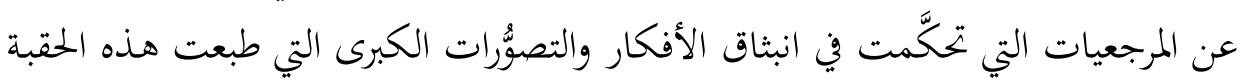
أو تلك في هذين الفكرين.

وطبيعة البحث تدور حول بيان مفهوم الإنسان من خلان الفين تقصّي المرجعيات التي

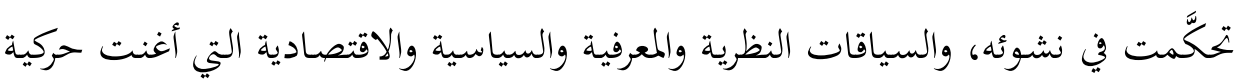

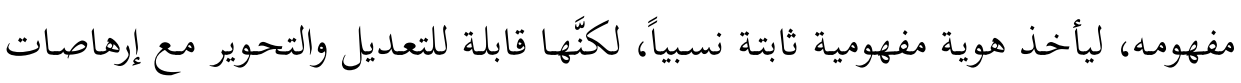

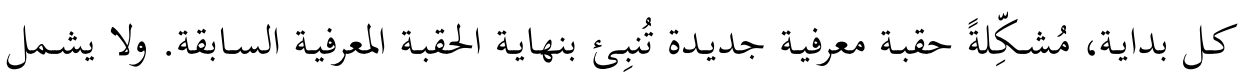

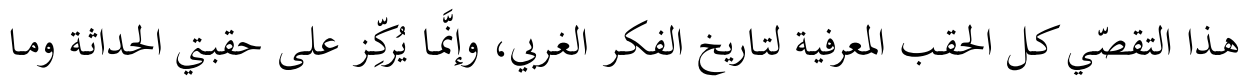
بعدها، مع الحرص على استدعاء التصوُّر الإسلامي؛ نقداً، وتنظيراً، ومقارنةً.

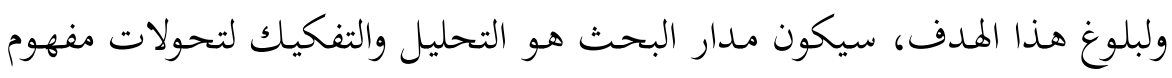

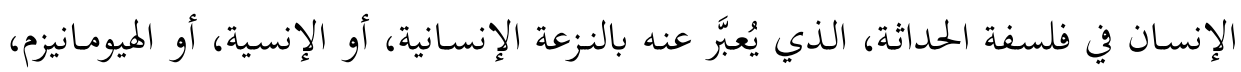

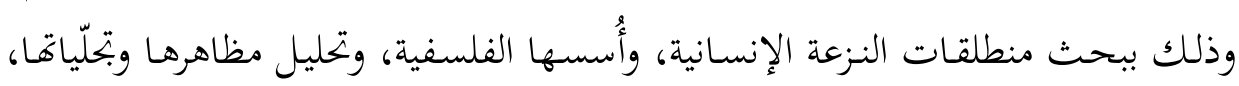

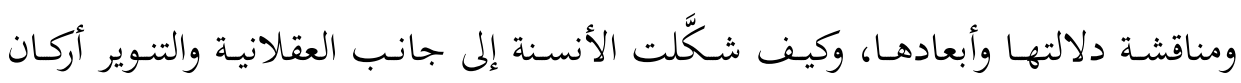

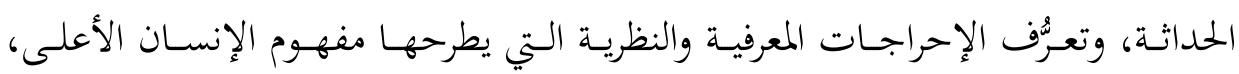

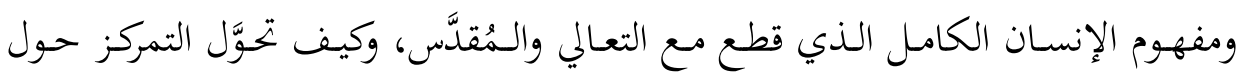

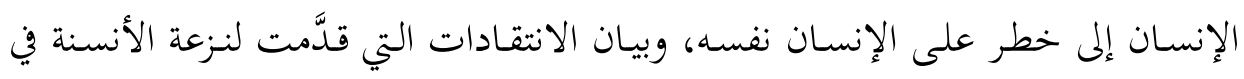


الفكر ما بعد الحداثي، الذي رفع شعار موت الإنسان، أو هاية الإنسان مع فوكو، وقبله نيتشه وهيدغر، وفلاسفة مدرسة فرانكفورت.

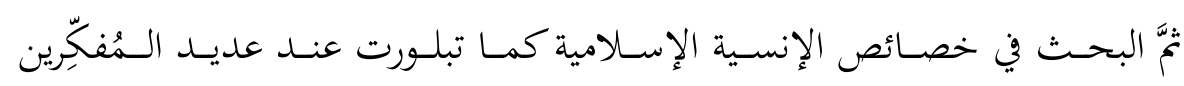

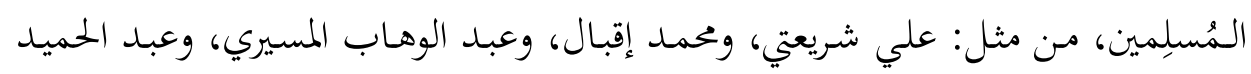

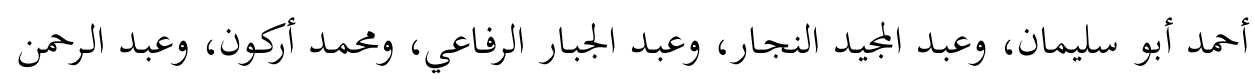

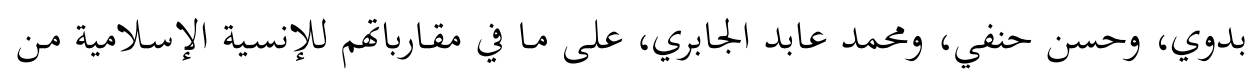
تمايزات واختلافات.

ولا تكتمل عمليـة تحليل مفهـوم الإنسـان في الفكـر الغربي مـن دون الوقوف على لهـ

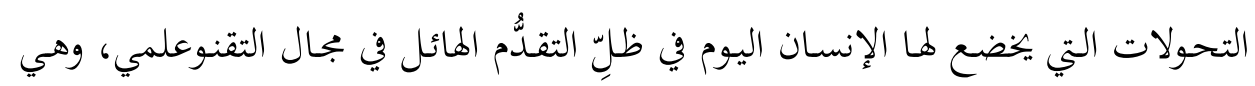

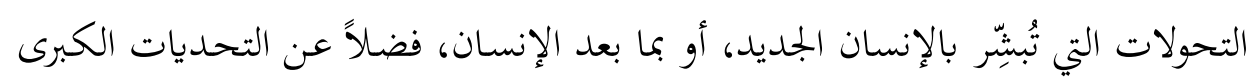

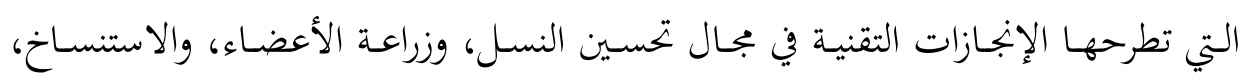
وغير ذلك مـن المشروعات المستقبلية، والمفاهيم التي ترسَّخت منذ قرون طويلة بوصفها

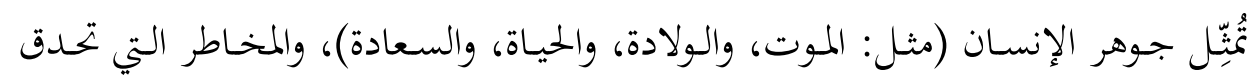
بالإنسان نتيجة التقنيات الجلديدة التي تُطبَّق عليه.

أولاً: النزعة الإنسانية (الدلالة، والسياق)

تُُبِّل النزعة الإنسـانية، إلى جانـب العقلانيـة والعلمانيـة والتاريخيـة، مفهوماً مركزياً في

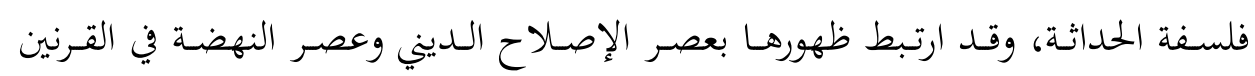

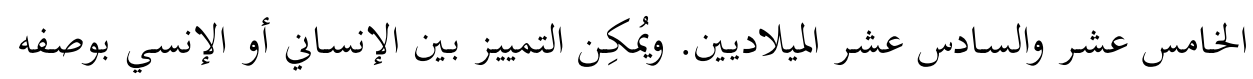

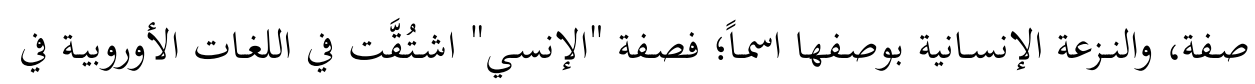

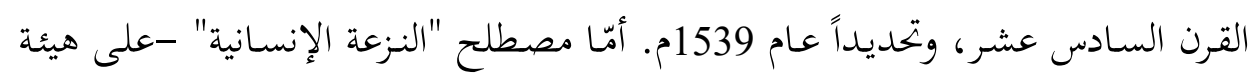

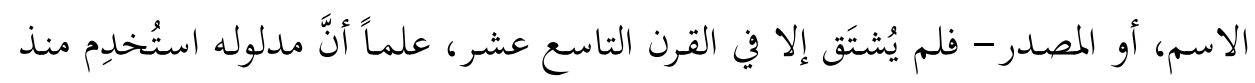

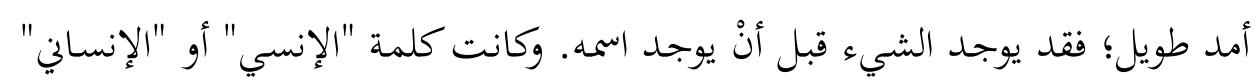


تُطلَق على البحّاثة المُتبحِّرين في العلم، وبخاصة في علوم الأقدمين (اليونان، والرومان)،

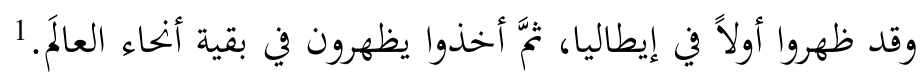
فالموقف الإنساني في معناه الأصيل يدل على دراسة نصوص العصور القديمة اليونانية

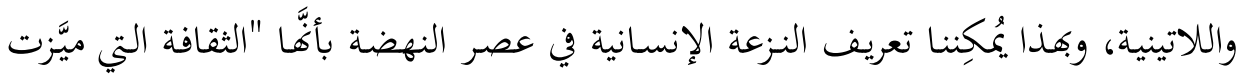

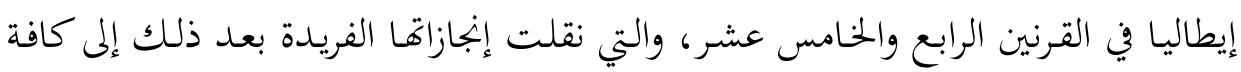

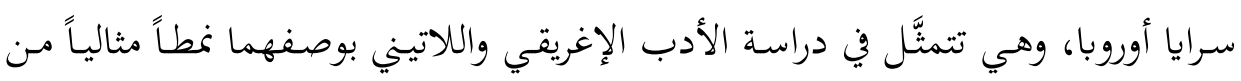
التربيـة والحضـارة. إنَّ الموقـف الفكـري المركزي للنـزعة الإنسـانية هـو الرجـوع إلى أصـالة

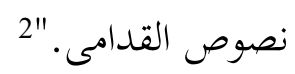

والرجوع هنا يحمل دلالة القفز على العصر الوسيط أو العصر المدرسي؛ ما أحدث

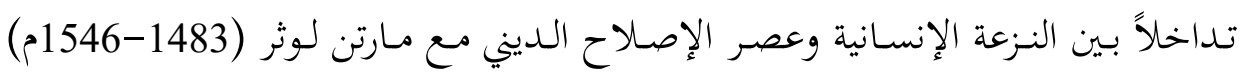

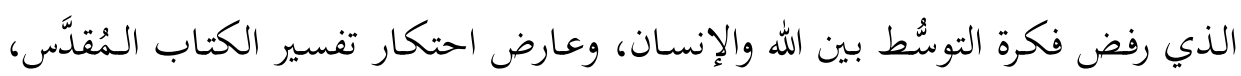

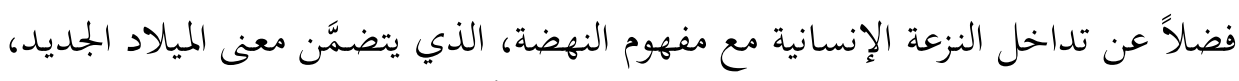
بالقفز على العصور الوسطى، والعودة إلى البدايات الأُولى اليونانية والإغريقية.

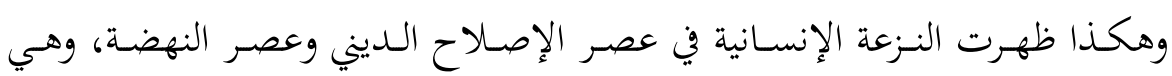

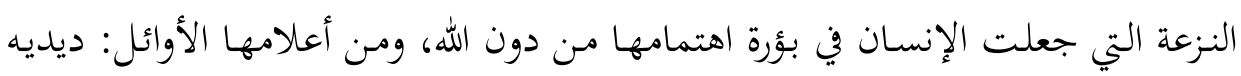
إيراسم (1469-1536م) الذي سوَّى بين الفلسفة واللاهوت بوصفهما وسيلتين للمعرفة دورة الإنس

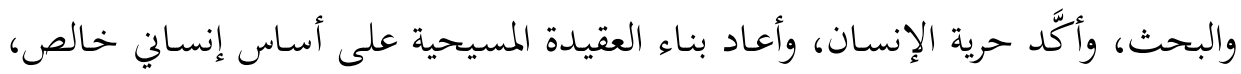

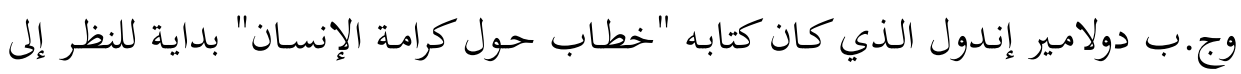

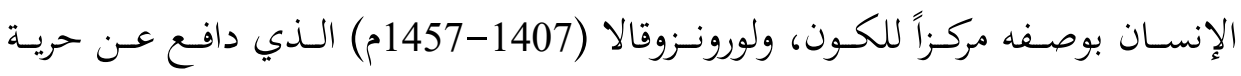
الاختيار بوصفه حقاً طبيعياً لإِنسان.

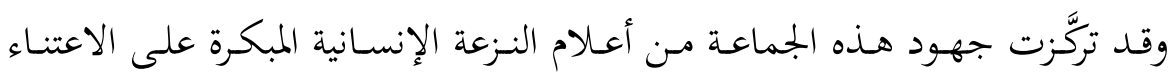

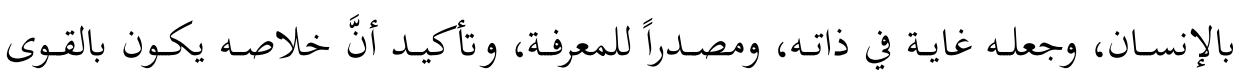

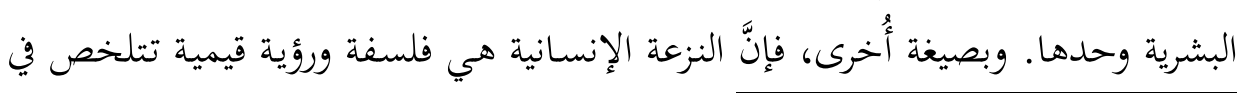

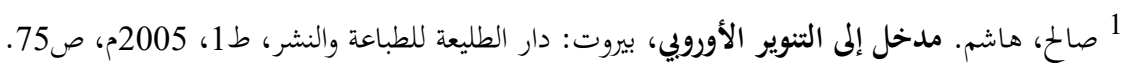
2 Michel Bloy, dictionnaire des concepts philosophiques, Larousse ,CNRS ,2006, $\mathrm{p}, 375$. 
المجهود العقلي والنظري الذي يسعى إلى تأكيد الإنسـان بوصفه قيمة عليا، تصدر عنه الاجتهادات لفهم الإنسان والمجتمع البشري كله، وترجع إليه.

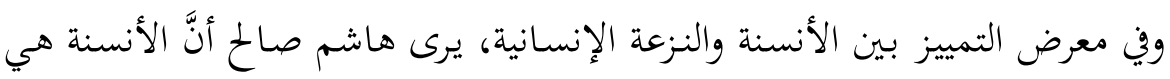

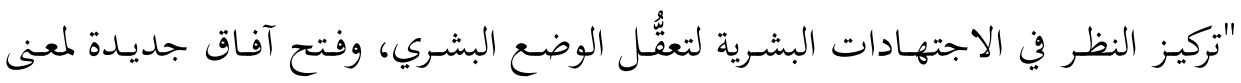

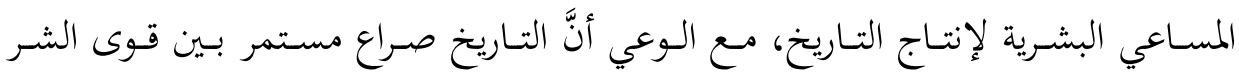

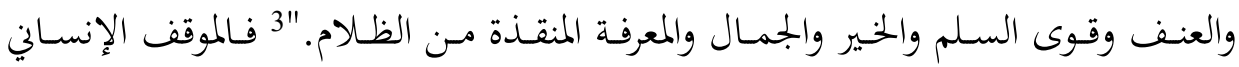

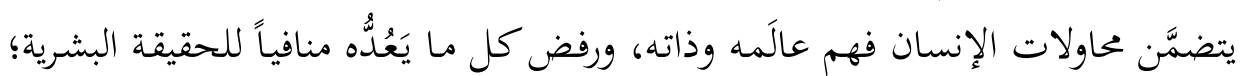

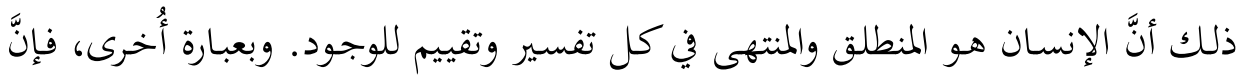

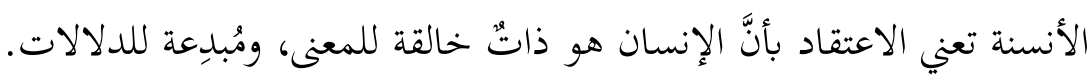

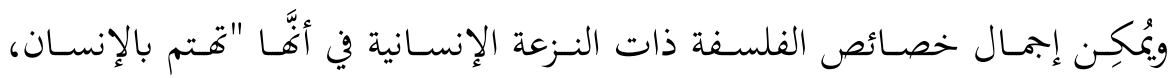

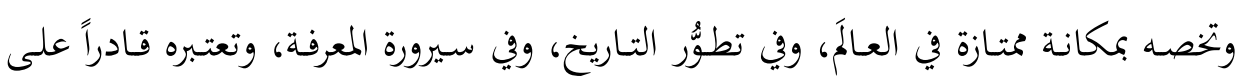

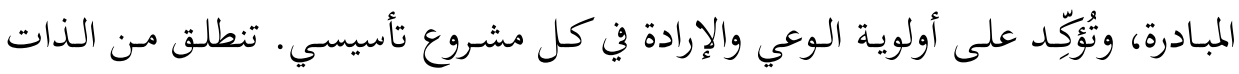

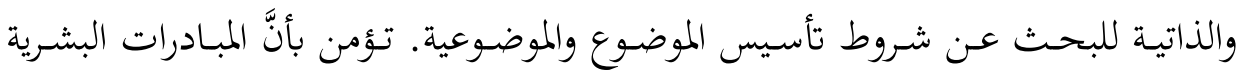

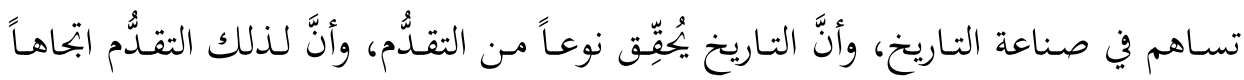
ومعنى مرتبطين بفعاليات وأهداف البشرية."

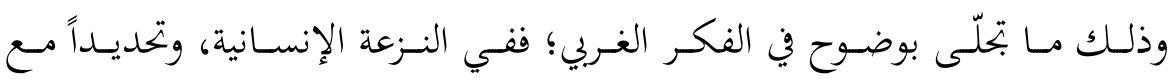

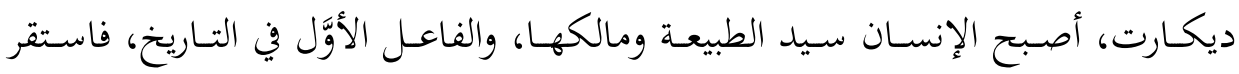

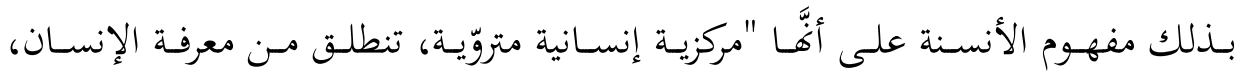

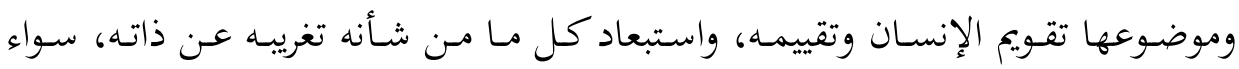

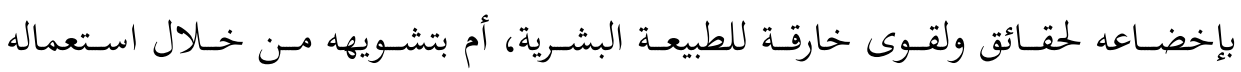

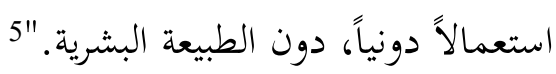

3 أركون، محمد. معارك من أجل الأنسنة في السياقات الإسلامية، ترجمة: هاشم صالح، بيروت: دار الساقي، ط2،

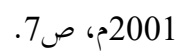
4 الدواي، عبد الرزاق. موت الإنسان في الحطاب الفلسفي المعاصر، هيدغر، ليفي ستروس، ميشيل فوكو، بيروت:

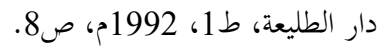

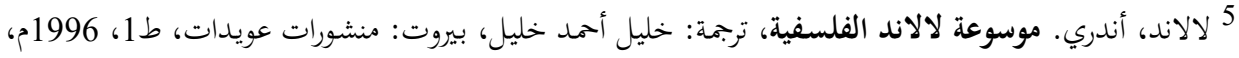




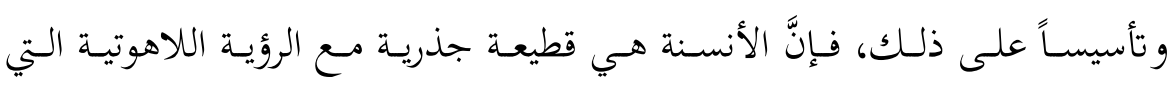

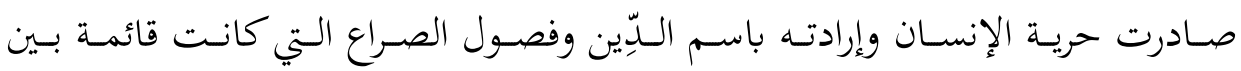

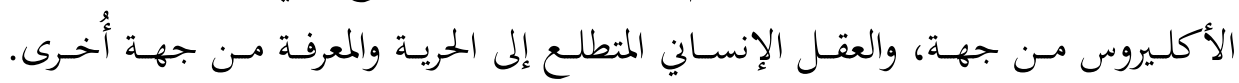

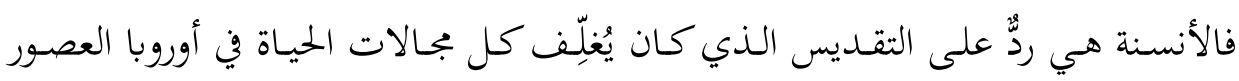

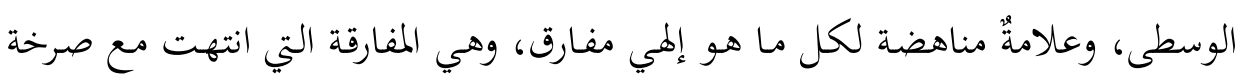

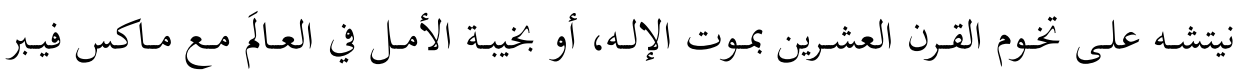
ومارسيل غوشيه؛ إذ لم يعد الإنسان في زمن الحداثة جوهراً تفسيرياً أو تأسيسياً ثابتاً، وإنَّا

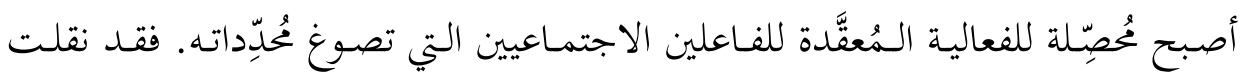
الحداثة الإنسان من مرحلة الشخص الذي خلقه الله عن طريق مديونية المعنى إلى مرحلة الشخص الفرد المواطن المرتبط بالدولة الحديثة عن طريق عقد اجتماعي الحسي قانوني.

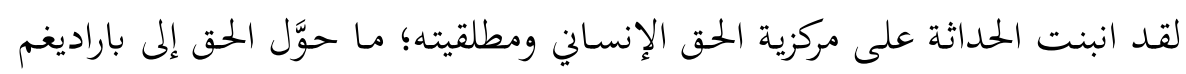
أساسي في الحداثة، ولا سيما أنَّ خطاب حقوق الإنسان في مواثيقه العالمية الكبرى جاء الإنس

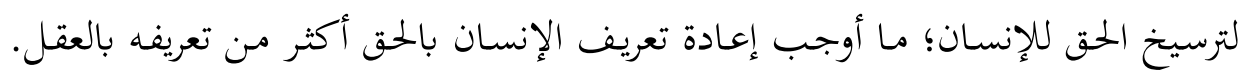

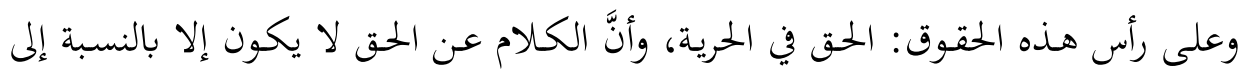

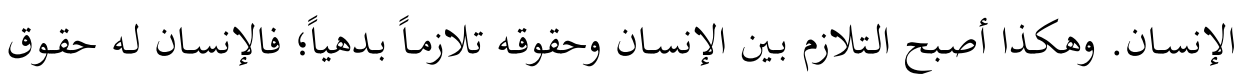
لأنَّهَ فقط إنسان.

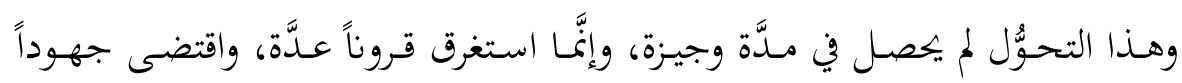

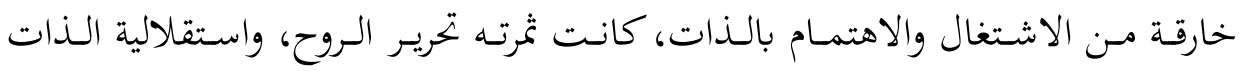

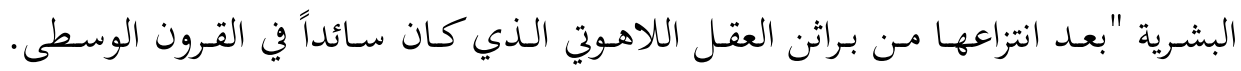

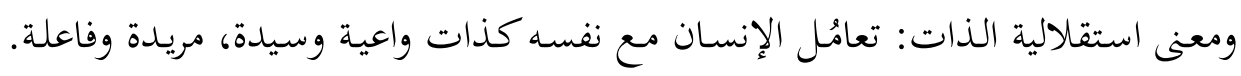

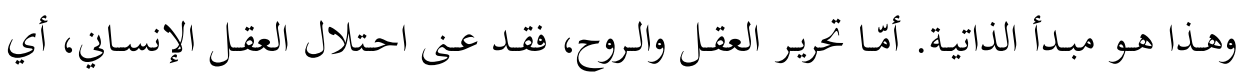

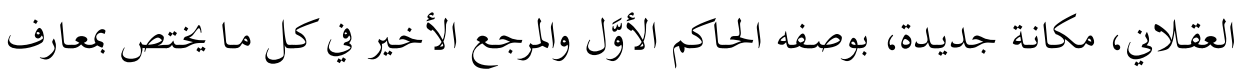

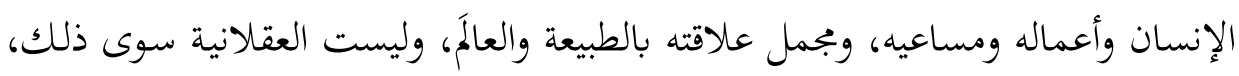




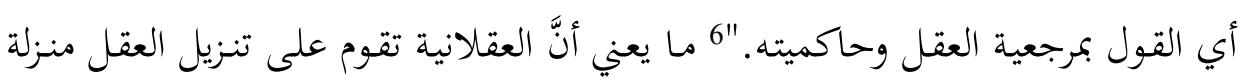

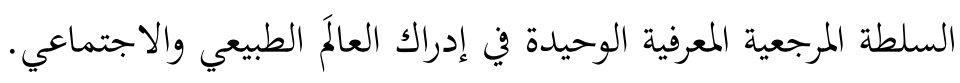

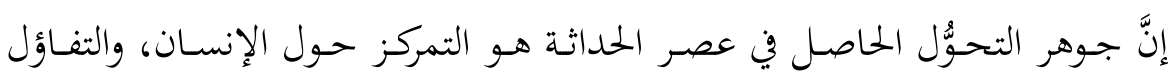

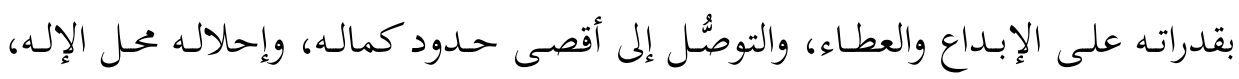

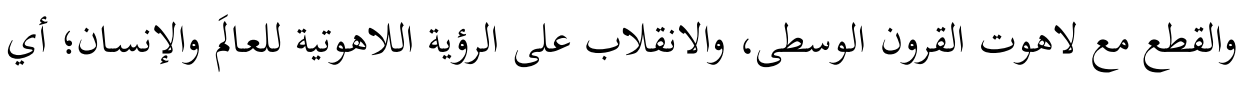

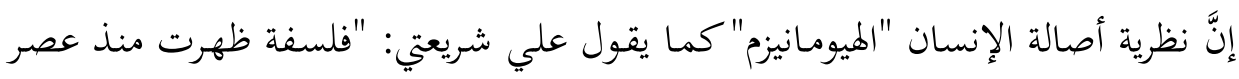

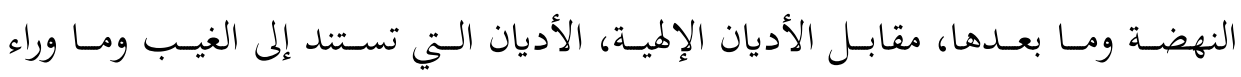

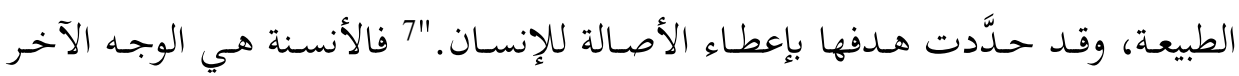

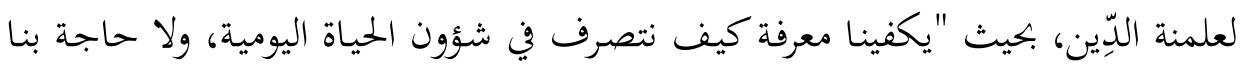

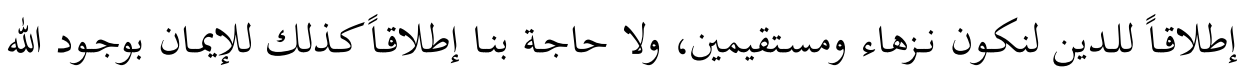

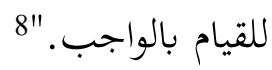
ووَفقاً لهذه المُحخِّدات، فإِنَّ الأنسنة هي فلسفة المحايثة في تعارُضٍ مع فلسفة التعالي

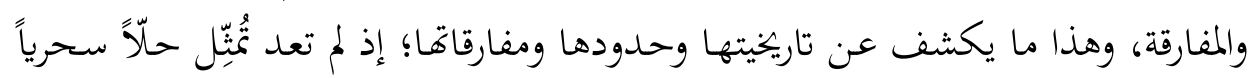

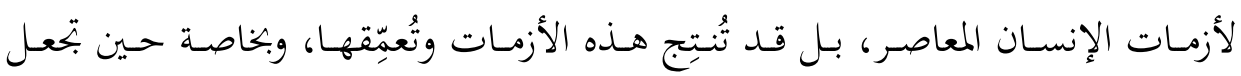

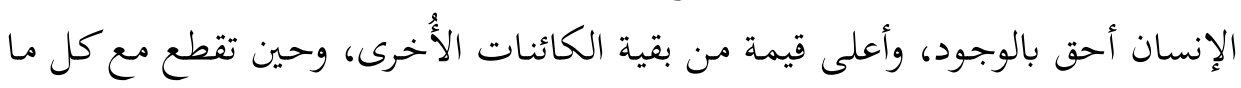

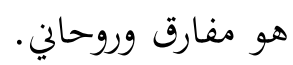
ولكنَّ هذا لا يعني أنَّ النزعة الإنسانية في الفكر الغربي -بجميع فروعها وتلويناقا-

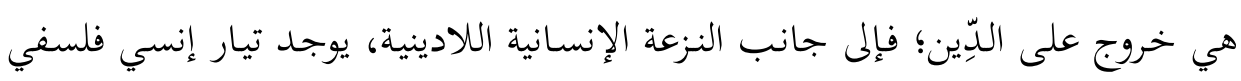

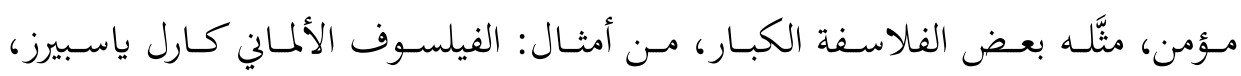

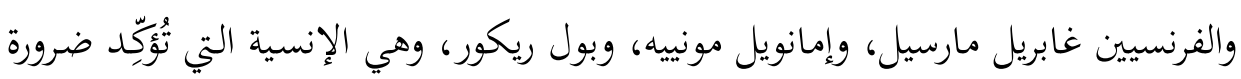

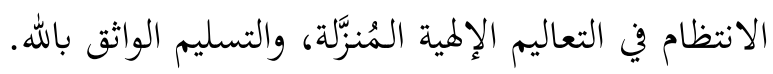

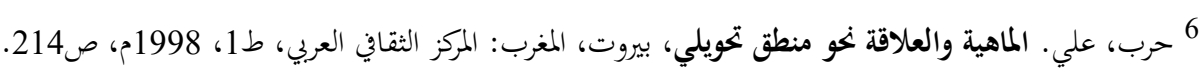

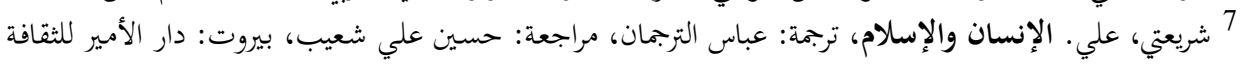

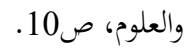
8 فيري، لوك. الإنسان المؤله أو معنى الحياة، ترجمة: عمد هاشم، المغرب: إفريقيا للنشر، 2002م، ص28. 
ثانياً: النقد ما بعد الحداثي للنزعة الإنسانية

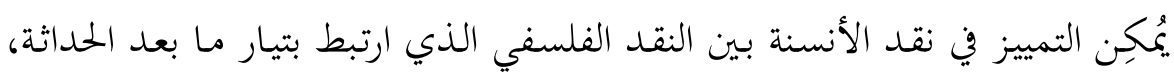

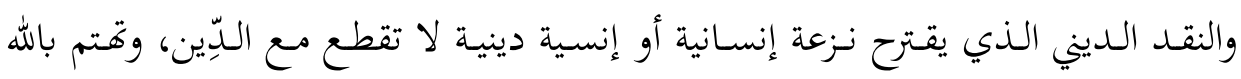

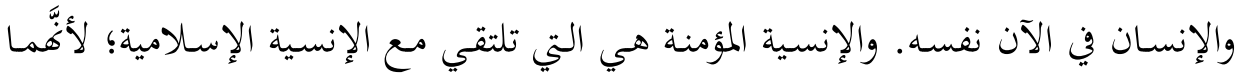
تشتركان في عدم مناهضة كل ما هو فوقي وميتافيزيقي.

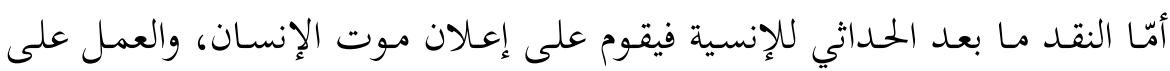

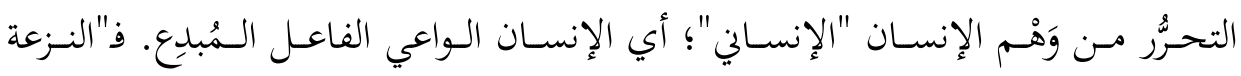

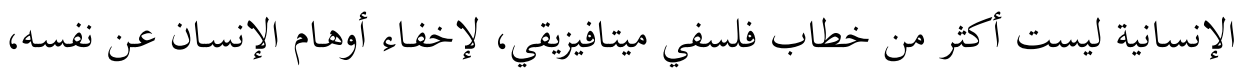

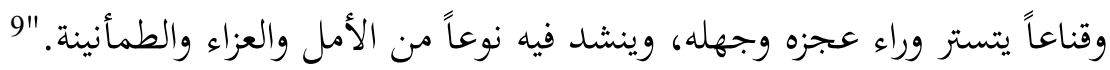

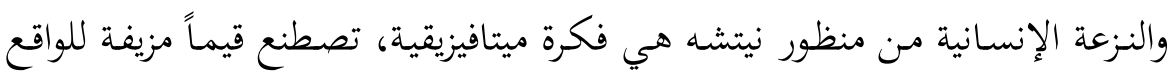

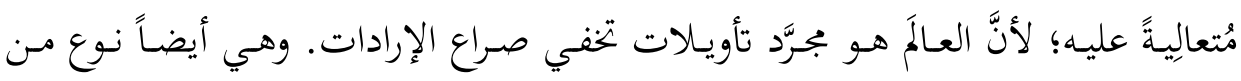

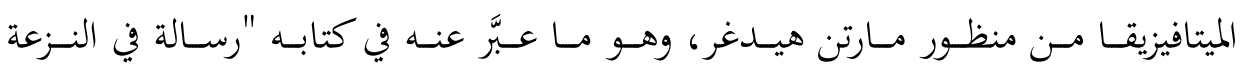

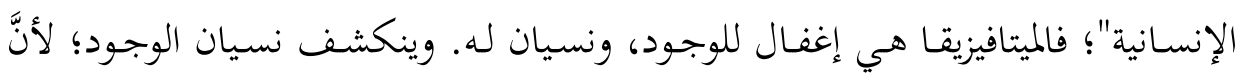

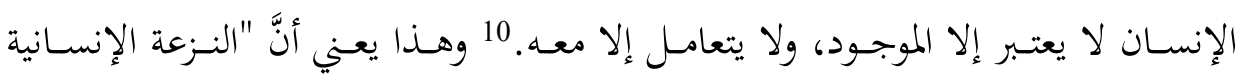

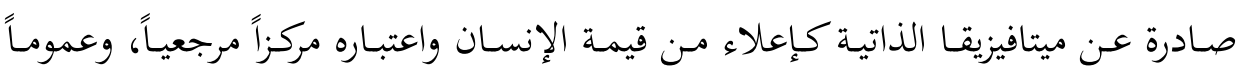

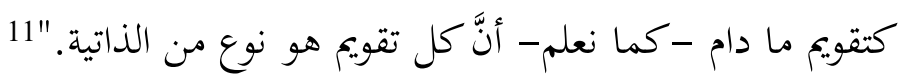

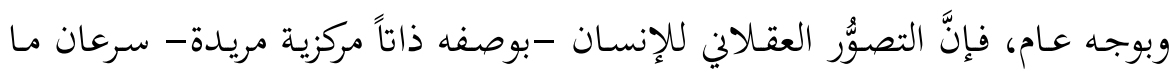

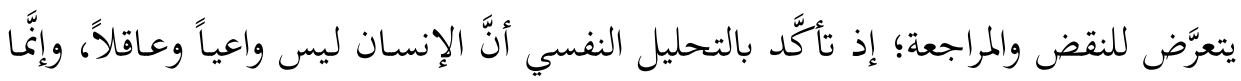

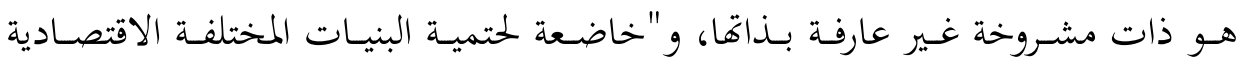

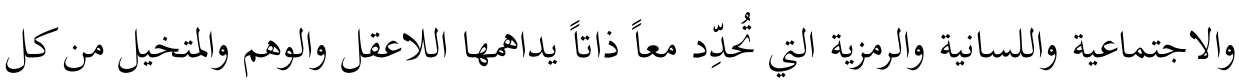
9 9 الدواي، موت الإنسان في الحطاب الفلسفي المعاصر، هيدغر، ليفي ستروس، ميشيل فوكو، مرجع سابق، ص22. (22. 10 ابن عبد العالي، عبد السلام. أسس الفكر الفلسفي المعاصر، المغرب: دار توبقال للنشر، ط2، 2000م،

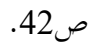
11 فاليري، لوك، ورونو ألان. "حقوق الإنسان موضوع للتفكير الفلسفي والأسس الفلسفية لخطاب حقوق الإنسان"،

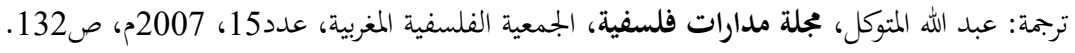




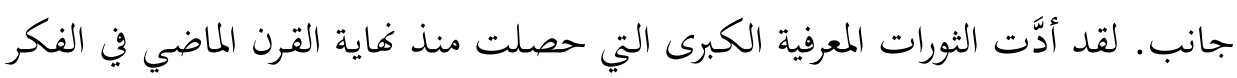

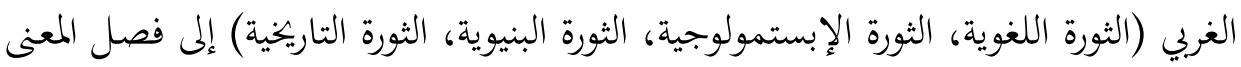

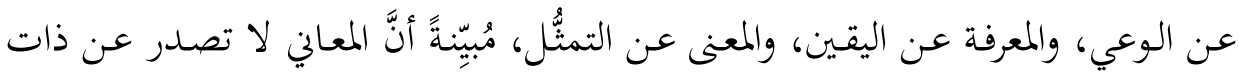

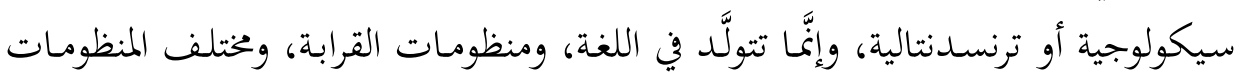

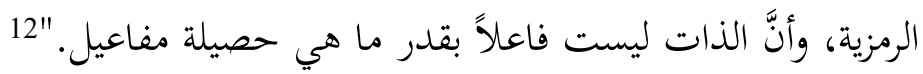

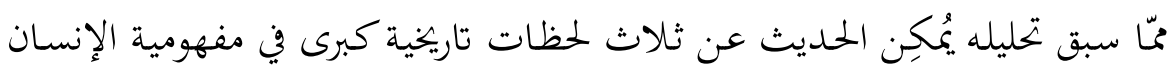

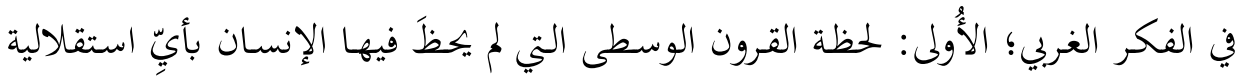

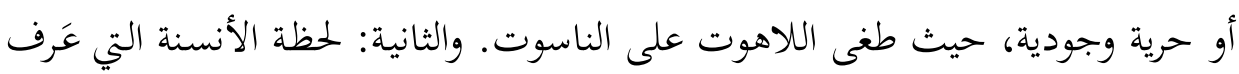

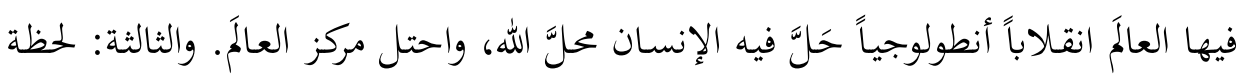

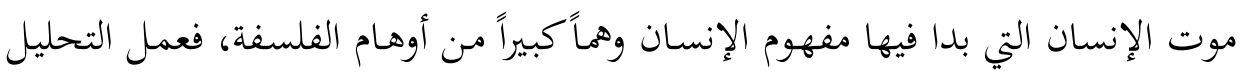
النفسي والفلسفة البنيوية وخطابات ما بعد الحداثة معاً على نقده وبيان بطان الإنسان الفانه.

\section{ثالثاً: الإنسية الإسلامية}

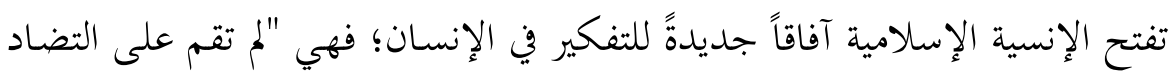

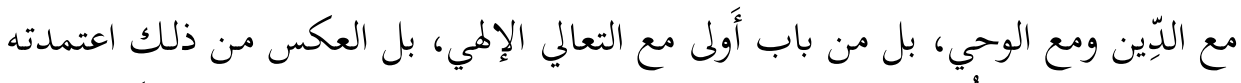

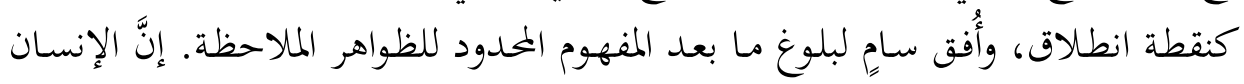

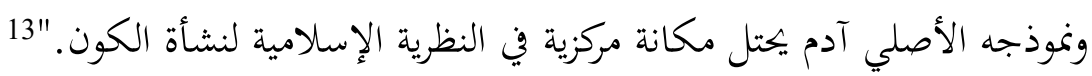

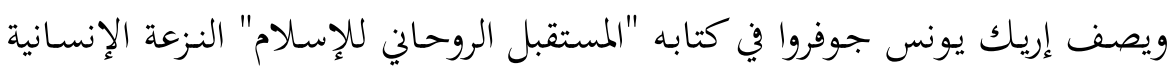

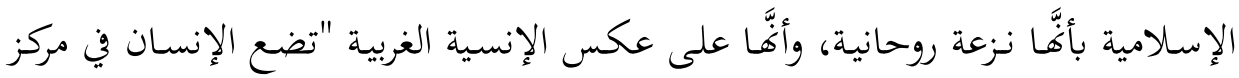

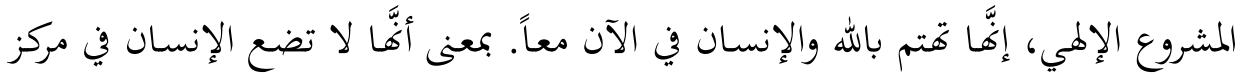

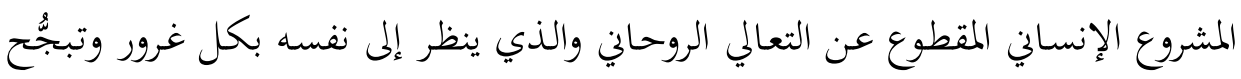

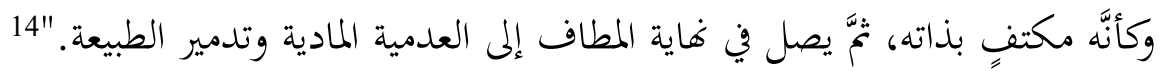

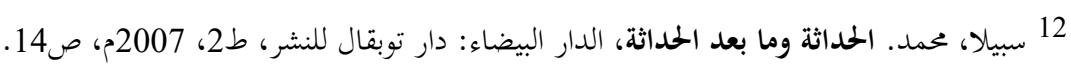

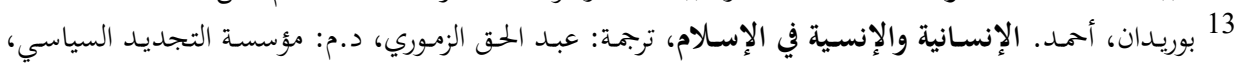
2015 2014، صوب. أحد. الاند 14 14:جوروا، أريك يونس. المستقبل الروحاني للإسلام، ترجمة: هاشم صالح، مراجعة: أسامة نبيل، القاهرة: المركز

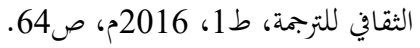


وهذا يعني أنَّ الإنسان في التصوُّر الإسلامي ظلَّ يحتل المركز، ولكنْ ليس على طريقة

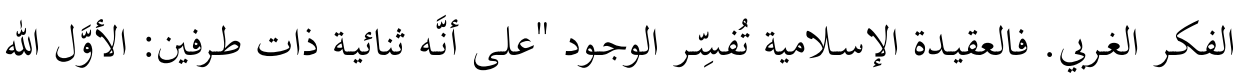

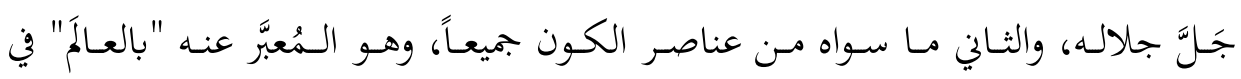

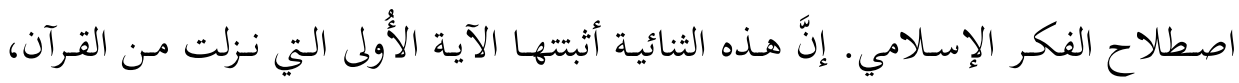

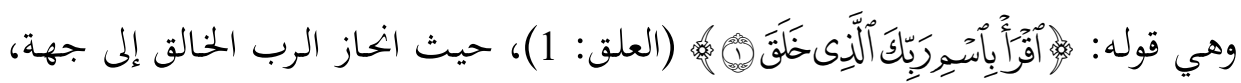

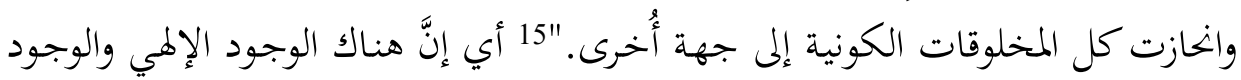

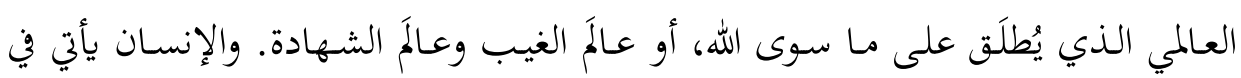

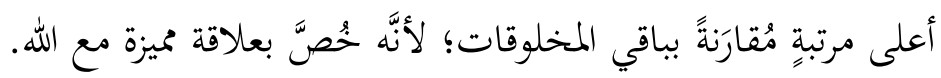

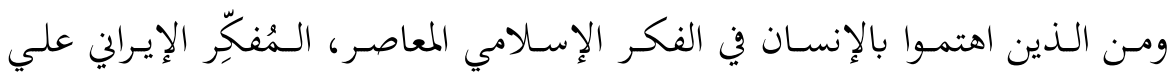

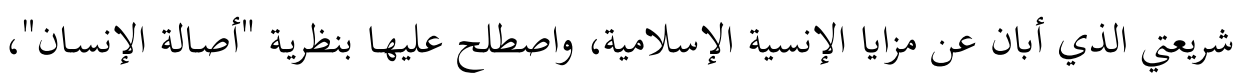

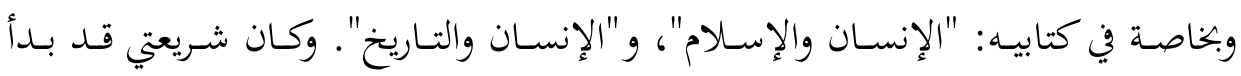

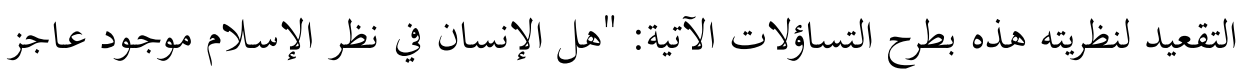

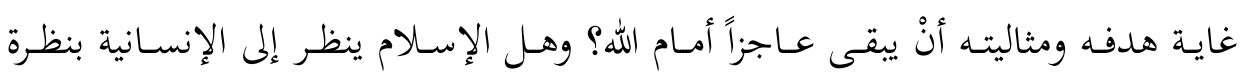

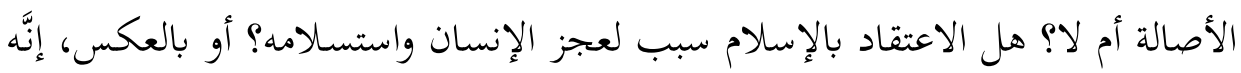

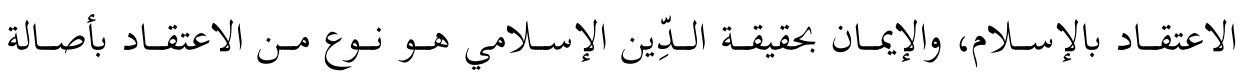
الإنسان، والاعتراف بقيمته وعظمة خصائصه وقدراته. "16

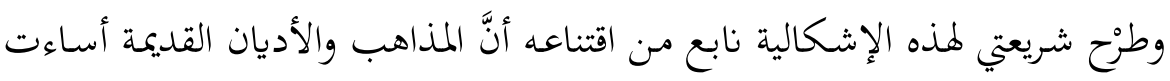

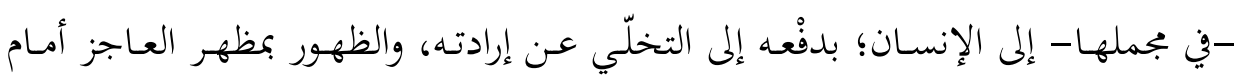

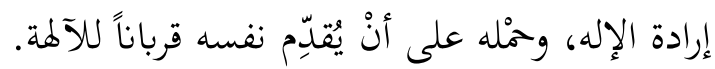

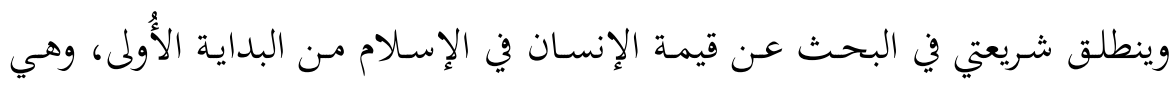

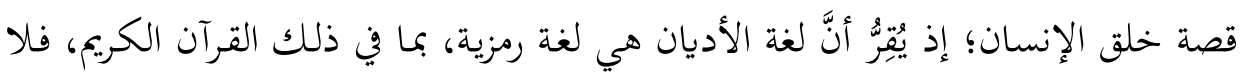

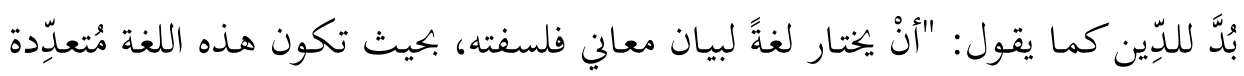

15 النجار، عبد الجيد. خلافة الإنسان بين الوحي والعقل: بحث في جدلية النص والعقل والواقع، واشنطن: المعهد

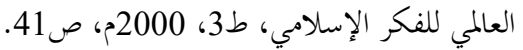

$$
\begin{aligned}
& 16 \text { شريعتي، الإنسان والإسلام، مرجع سابق، صالإن، ص11. }
\end{aligned}
$$




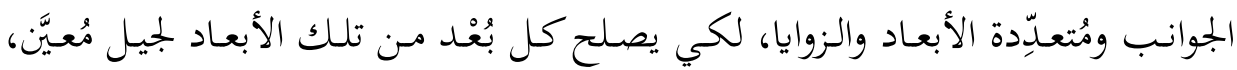

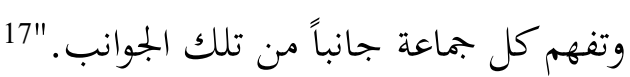

وعلى هذا، فمكانة الإنسـان عظيمة في الإسلام؛ لأنَّهَ خليفة الله في أرضها، ونظرية "أصالة الإنسان" الغربية لم تفترض للإنسان هكذا قدسية وعظمة ورفعة، "بمعنى أنَّ رسالة

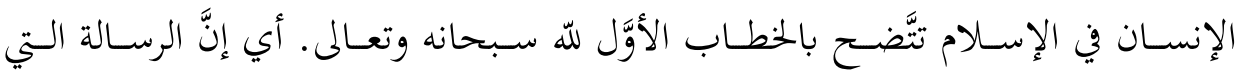
حلَّدها الله سبحانه وتعالى للكائنات يضطلع الإنسان لإنسان بمسؤولية أدائها باعتباره خليفة الله في أرضه. "18

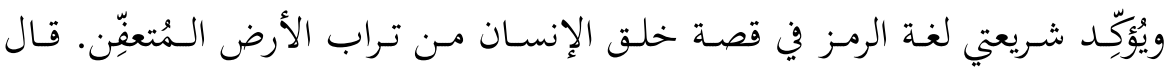

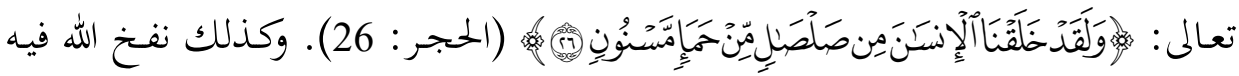

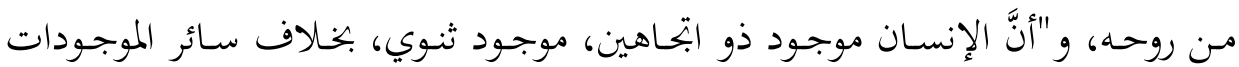

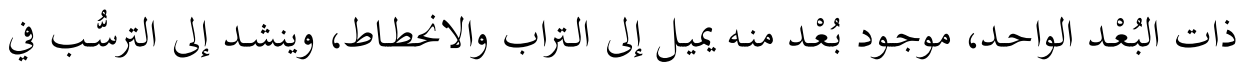

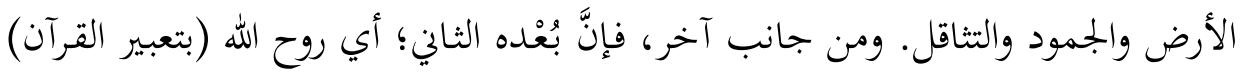

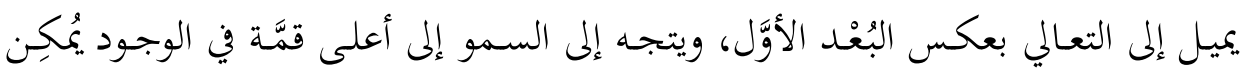
تصوُّرها؛ أي إلى الله."

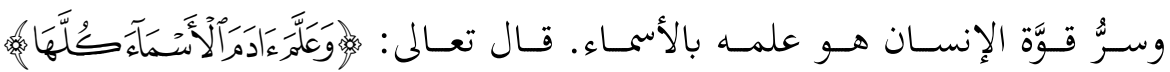

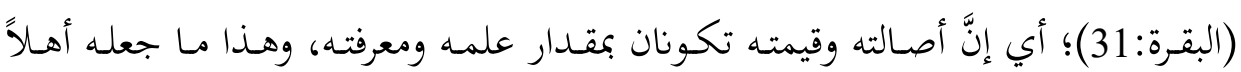
لحمل الأمانة، التي هي إرادة الإنسان، وحرية اختياره. "فالفضيلة الوحيدة التي يتميز بهـا

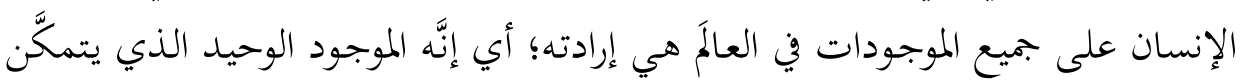

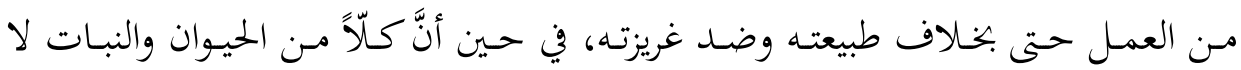

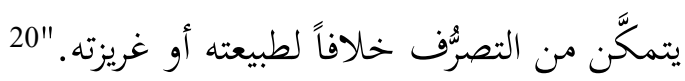

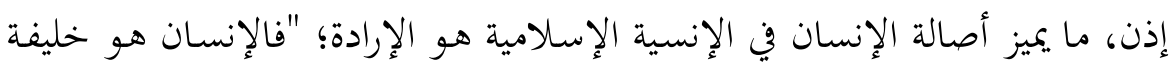

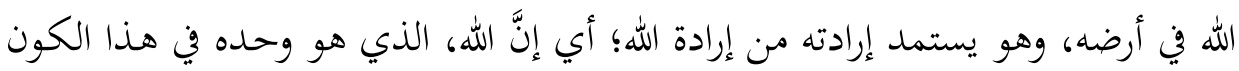

$$
19 \text { 19 } 19 \text { المرجع المرجع السابق، ص16، ص13. }
$$


لـه الإرادة المطلقـة وبإمكانه أنْ يفعل مـا يريــ حستى لـو كان خلافـاً للمنظومـة والقـوانين

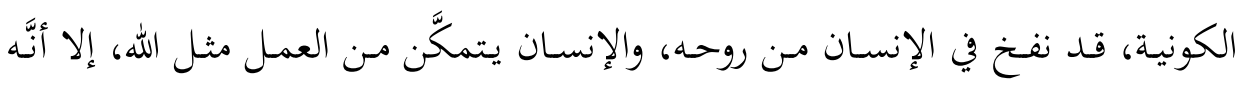

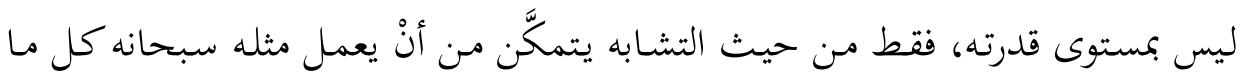

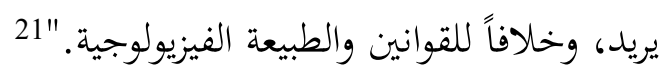

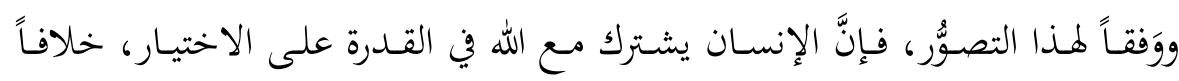

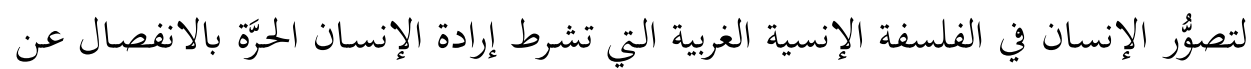

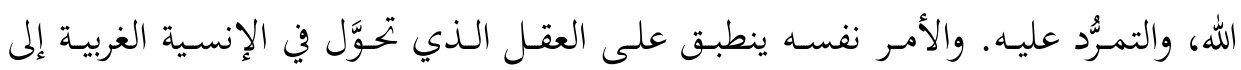

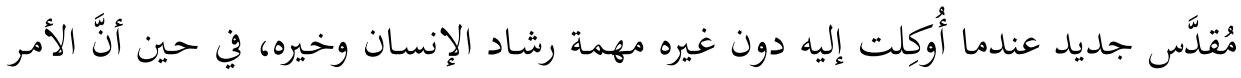

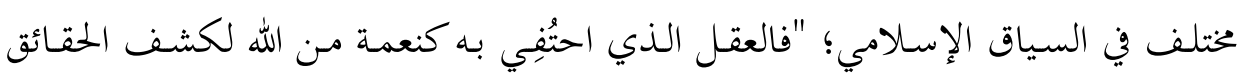

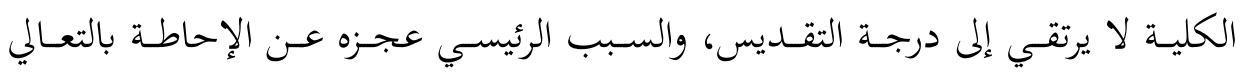
الإلهي."22" الحلينة

وبكسب شريعتي، فإنَّ الإنسان "يقف بين قطبين: الله والتراب، وبما أنَّهَ يمتلك الإرادة

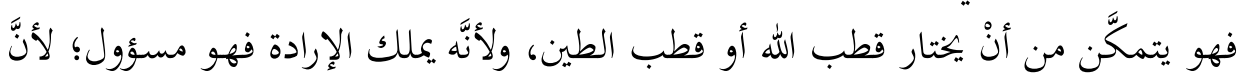

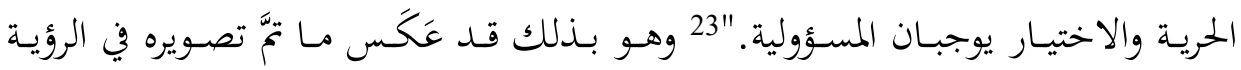

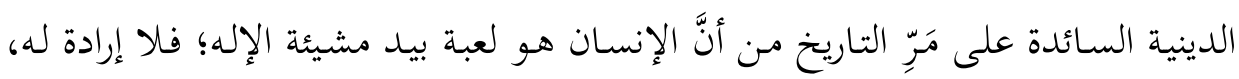

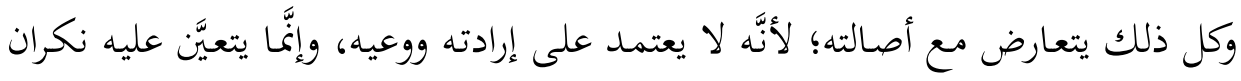

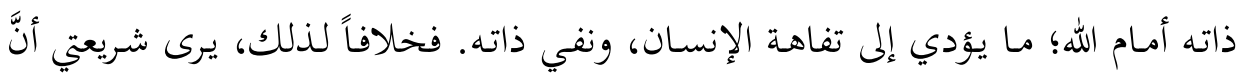

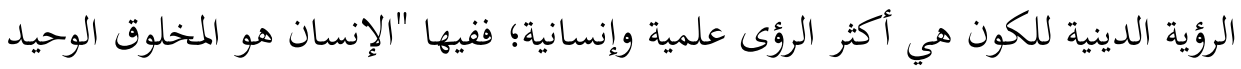

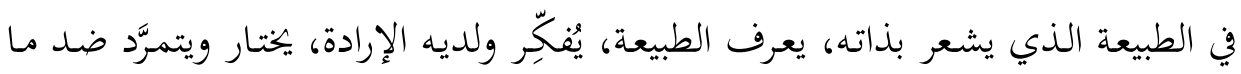

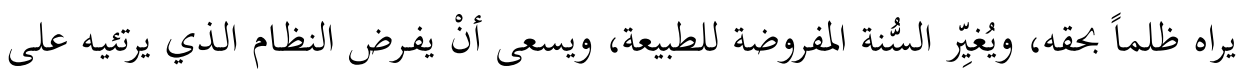

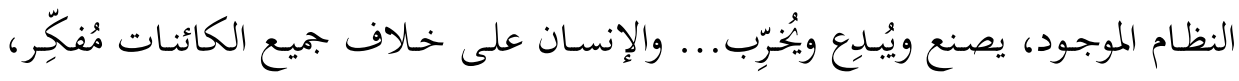

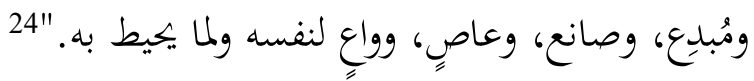

$$
\text { 21 21 المرجع السابق، ص23. }
$$

22 بوريدان، الإنسانية والإنسية في الإسلام، مرجع سابق، ص25.

$$
23
$$

24 شريعتي، علي. الإنسان والتاريخ، ترجمة: خليل ماليل علي، تحقيق وتحرير : محمد حسين بزي، العراق: دار الأمير للثقافة

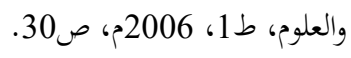




$$
\text { ويُحُدِدِد شريعتي ثلاث خصائص جوهرية للإنسان: }
$$

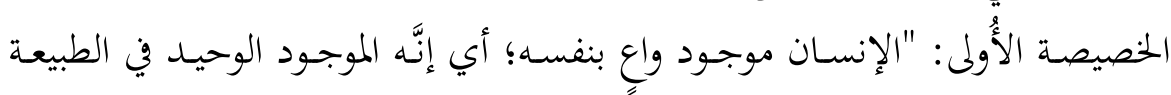

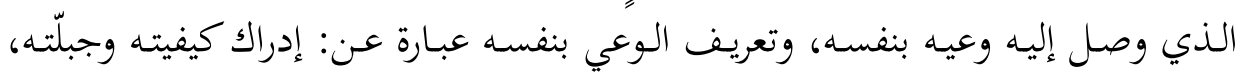

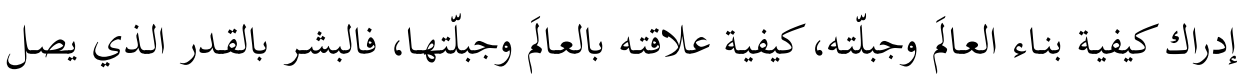
إلى الوعي بهذه الأصول الثلاثة يكون إنساناً. "25

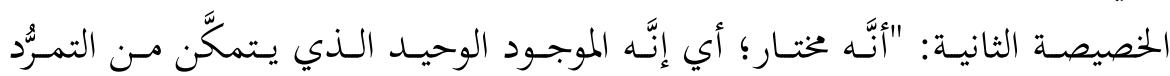

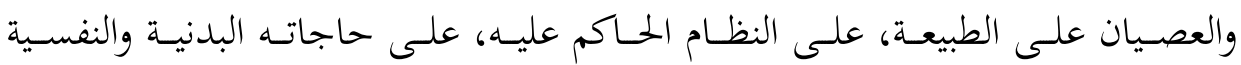

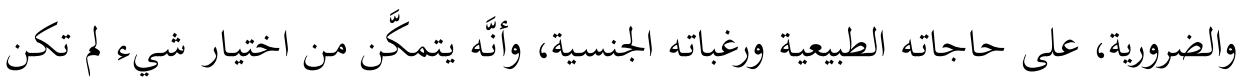

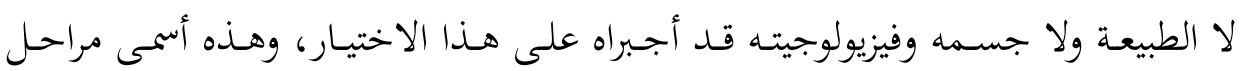
صيرورة الإنسان. "26

الخصيصة الثالثة: "إنَّ الإنسان موجود ومُبدِع، يُبدِع من أصغر الأشكال إلى أعظم

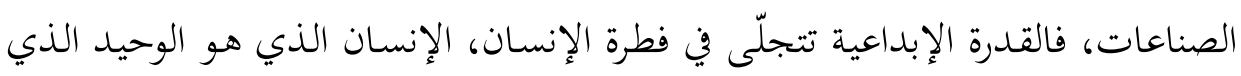
يصنع."27"

ويرى شريعتي أنَّ هذا "الإنسان يتمكَّن، على خهاف الطبيعة، أنْ يكون موجوداً،

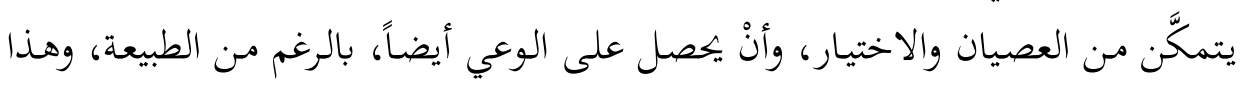

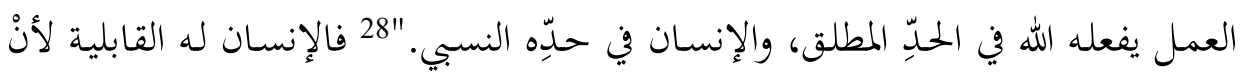

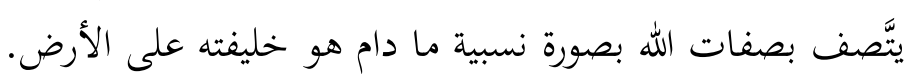

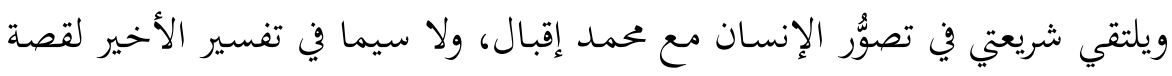

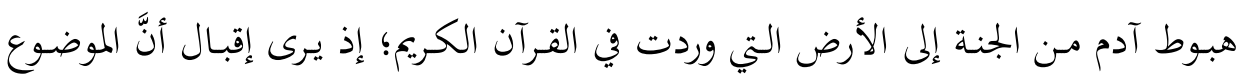

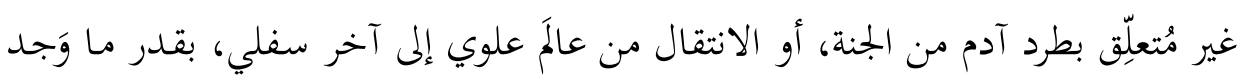

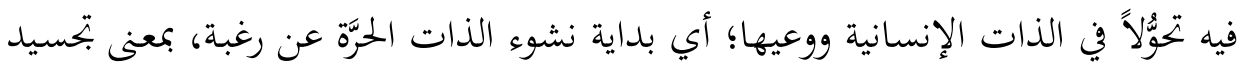

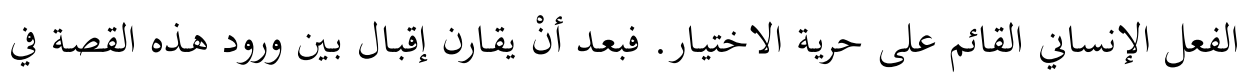

$$
\begin{aligned}
& 25 \text { شريعتي، الإنسان والإسلام، مرجع سابق، ص156. } \\
& 26 \text { المرجع السابق، ص156، الإنسان والإسالو. } \\
& 27 \text { المرجع السابق، صلمجع، ص157. } \\
& 28 \text { المرجع السابق، صلمجع، ص161. }
\end{aligned}
$$


التوراة والقرآن، ويبرز نقاط الاختلاف بين الروايتين، ومعنى الجنة، يقول: "إنَّ قصة آدم

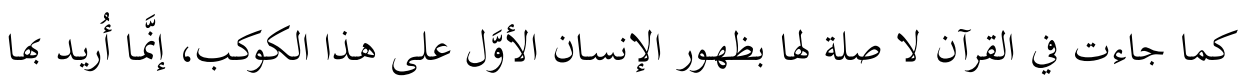

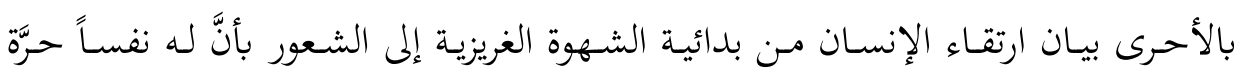

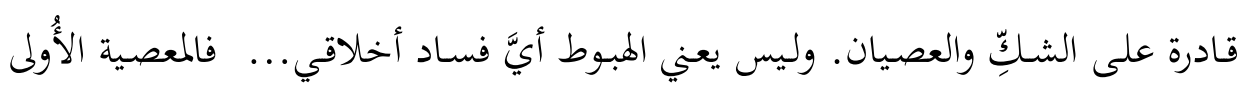

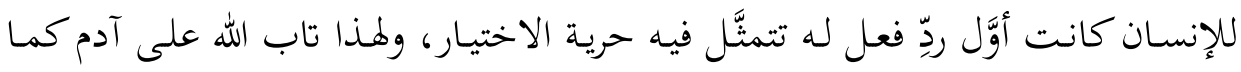

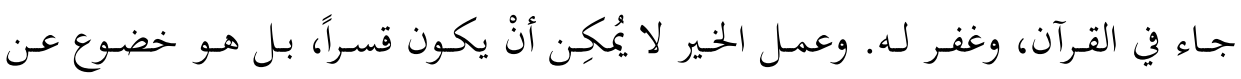

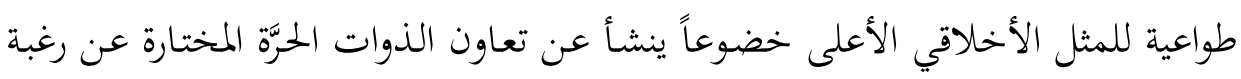

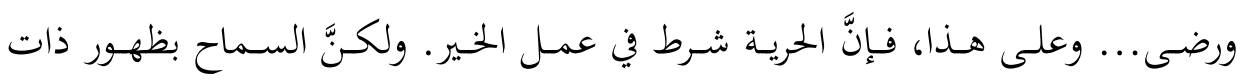

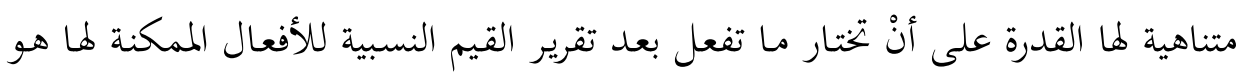

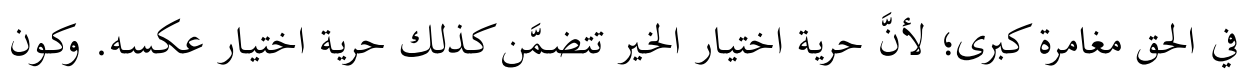
المشيئة الإلهية اقتضت ذلك دليل على ما لله من ثقة في الإنسان. "29

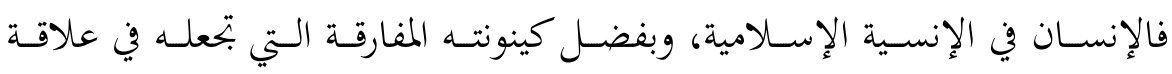
استخلاف مع الله، يتكشَّف وجهه الإنسي بوصفه سيداً للعالمَ، ومُبدِعاً للمعنى، ويتبوأ مكانة كبيرة في صناعة التاريخ. وهو -بحسب هذه الرؤية- ليس كائناً ذليلاً أمام الله، وإنَّا

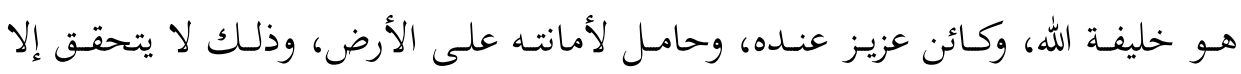

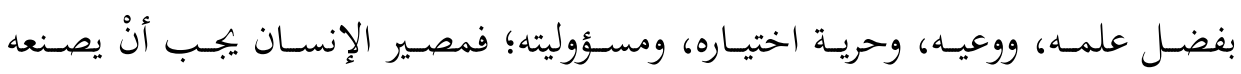
الإنسان نفسه، وبتلك الكيفية تتحقق أصالته التامة.

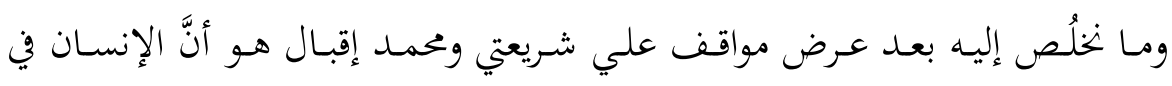

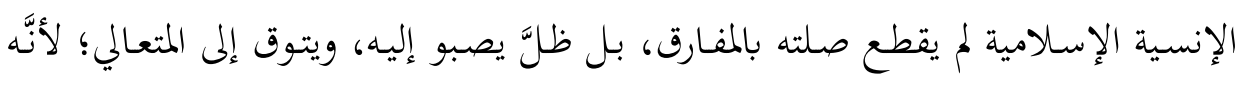

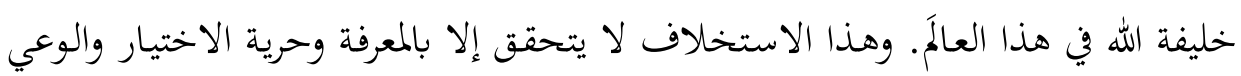

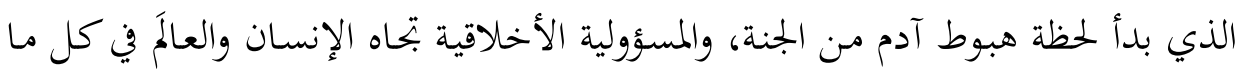

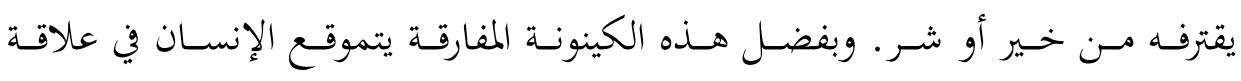
استخلافٍ لله تعالى، بعيداً عن كل سياق تناظرُ ضدي معه، أو عبودية ساذجة له؛ فقيم

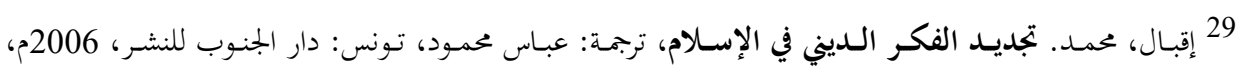




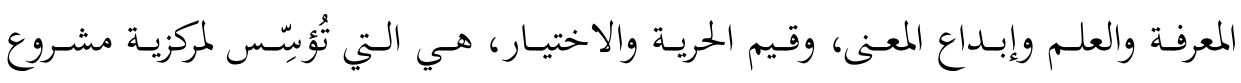

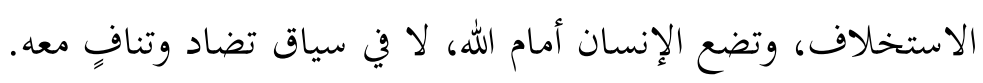

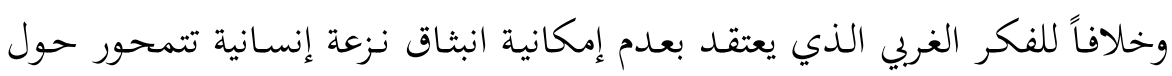

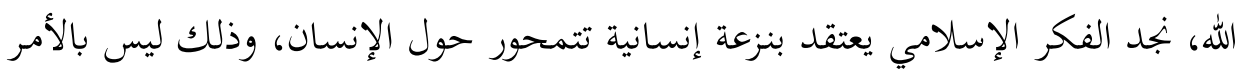

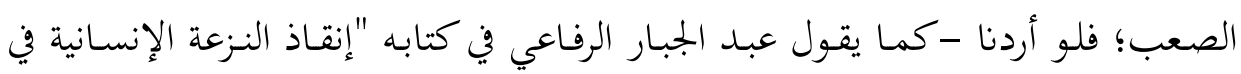

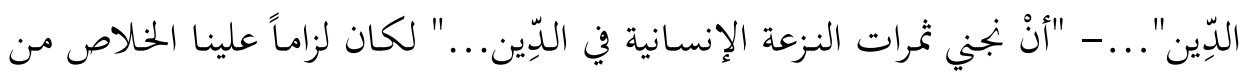

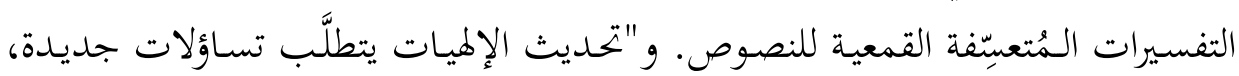

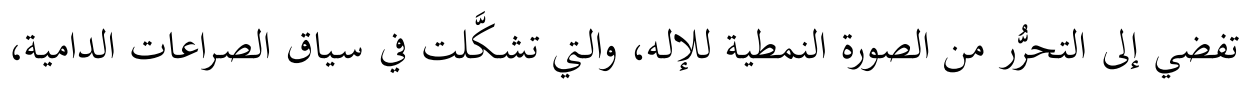

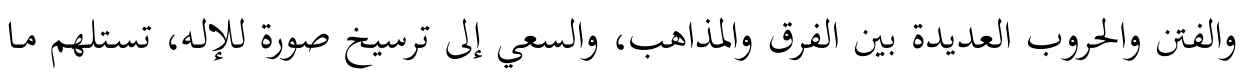

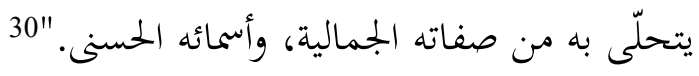

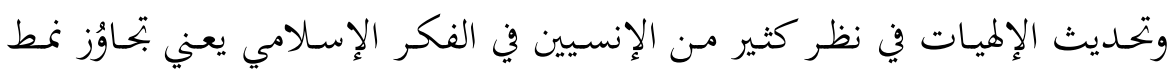

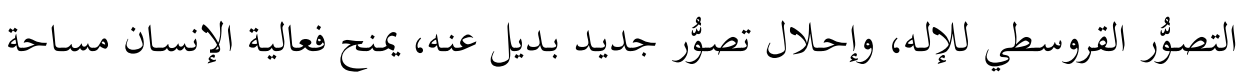

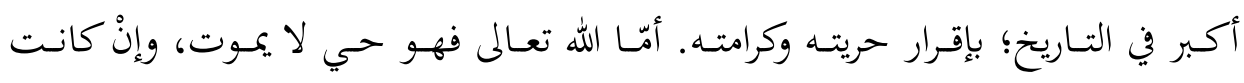

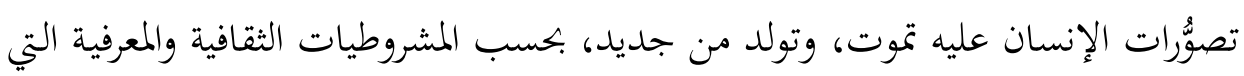

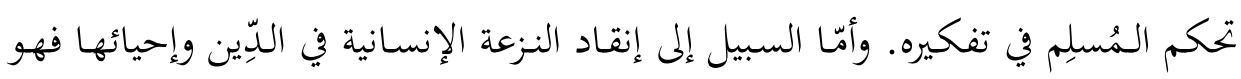

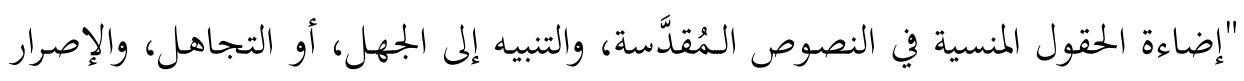

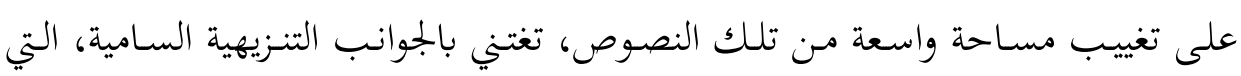

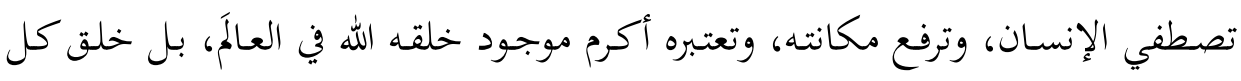

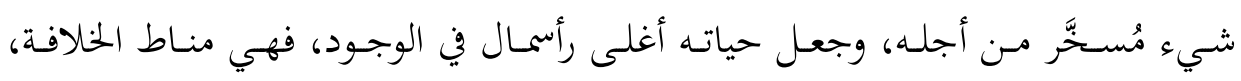

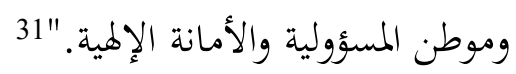

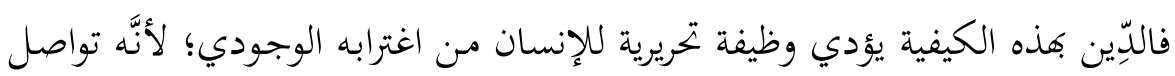

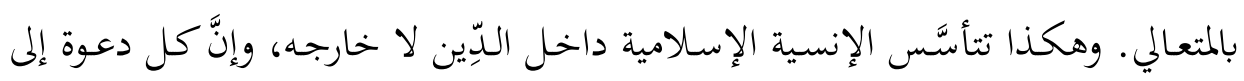
تفكيك المُقدَّس الديني تفضي فقط إلى مزيد من الظمأ الوجودي.

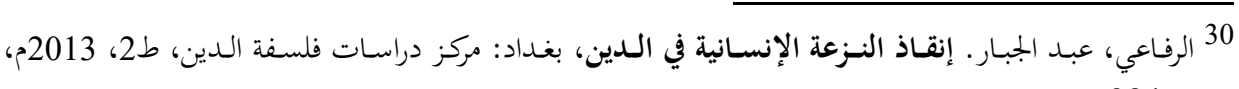
ص284. (28)

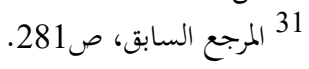




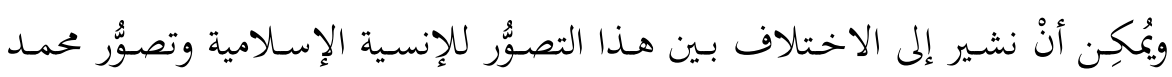

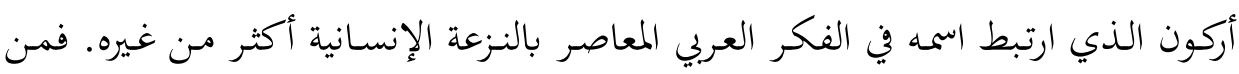

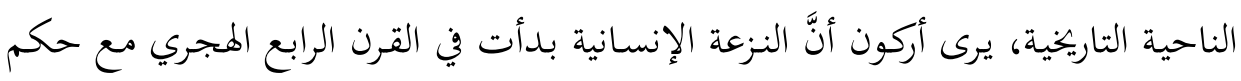

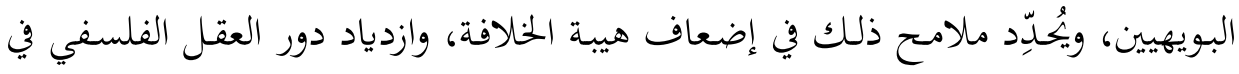

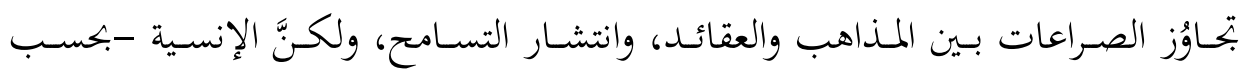

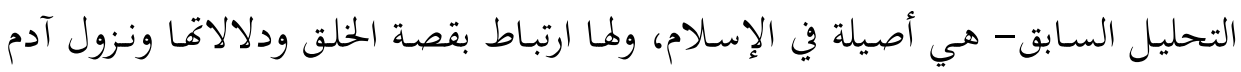
من الجنة إلى الأرض.

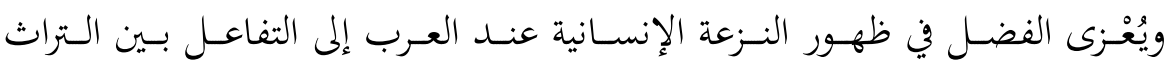

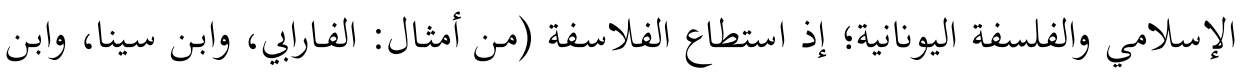

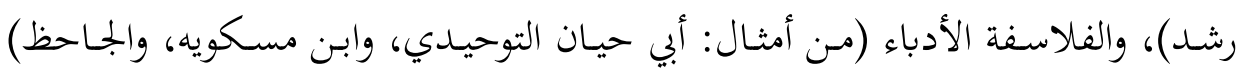

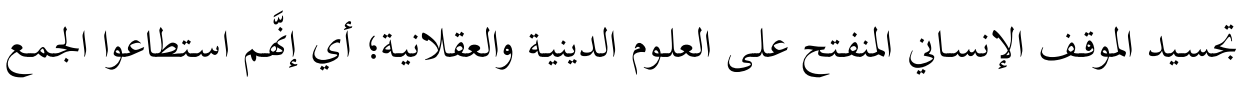

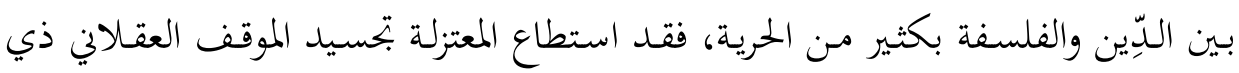

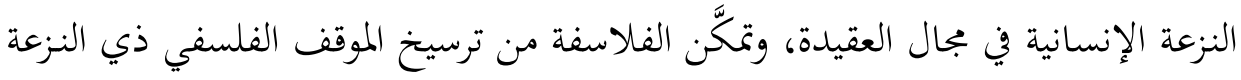

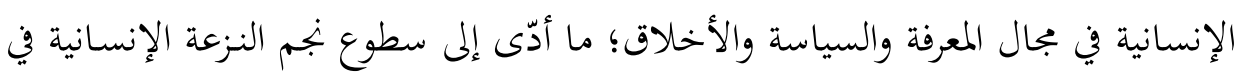

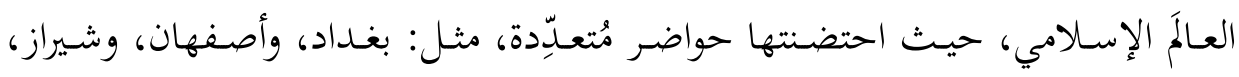
وقرطبة، وإشبيلية.

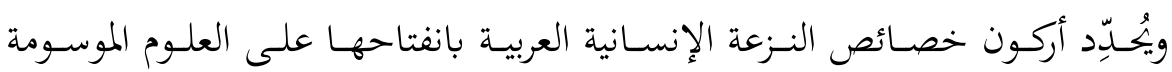

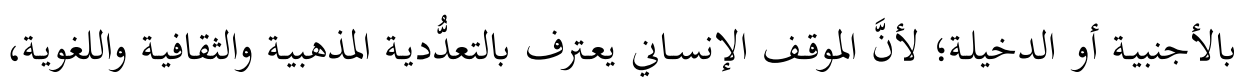

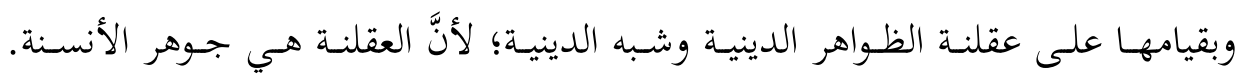

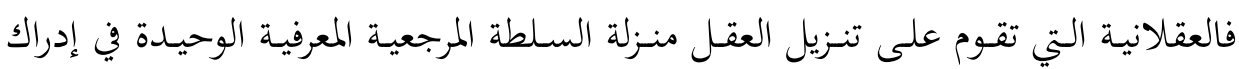
العالمَ، تجعل الإنسان هدفها الأوَّل والأخير.

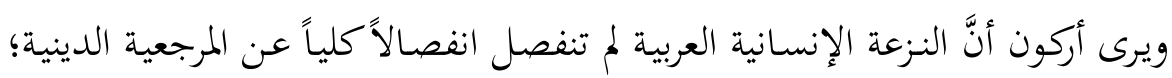

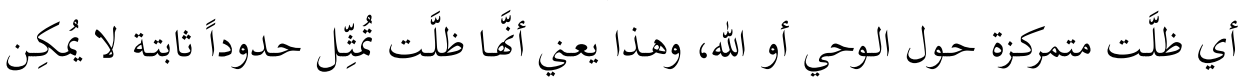

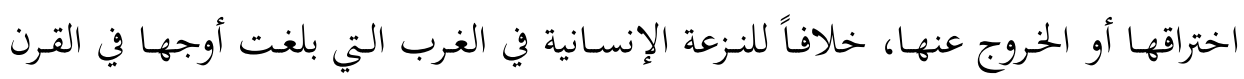


الثامن عشر، والتي تمَّ فيها الخروج عن الدِّين؛ أي كانت متمركزة على الإنسان، وذلك عن طريق اختراق الميتافيزيقا الغربية، وتفكيك مُسلَّماهما.

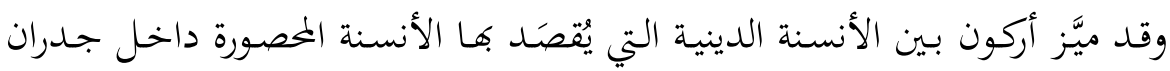

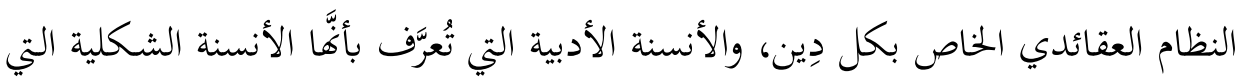
تكتفي بالتلاعب اللفظي، والتي تنفصل عن الحياة اليومية، والأنسنة الفلسفية التي تتميز

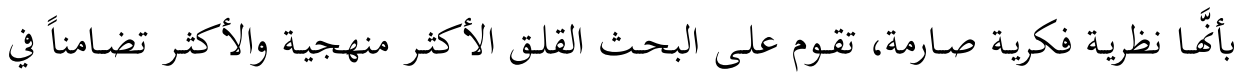
بحث حقيقة العالمَ والإنسان والله.

تمََّّ بحث أركون في أسباب تراجع النزعة الإنسانية في الثقافـة العربيـة، أو مـا يُسمّيه

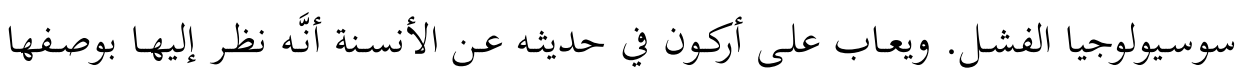

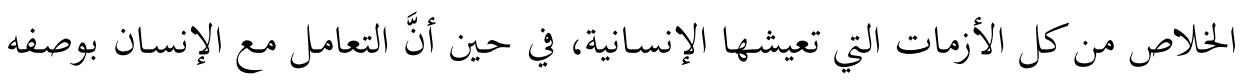

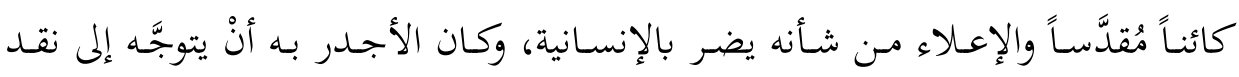

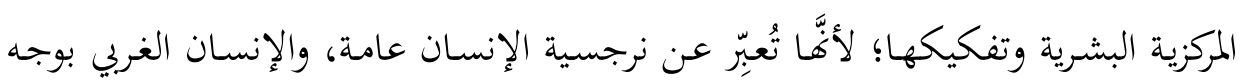
خاص، التي تضر بالإنسان والطبيعة.

\section{رابعاً: التقنية ورهان الإنسان الفائق}

يتميز زماننا الحاضر بسطوة غير مسبوقة للتقنية على الحياة والإنسان، تحوَّلت معها

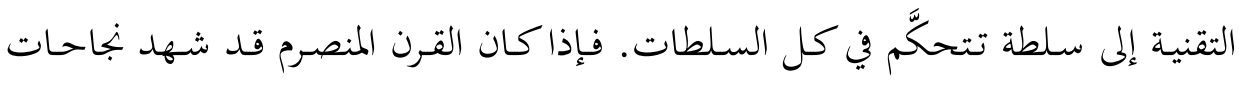

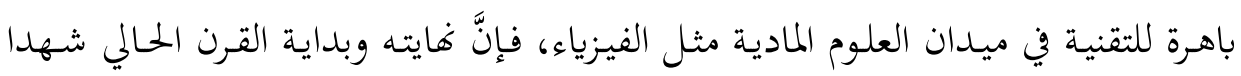

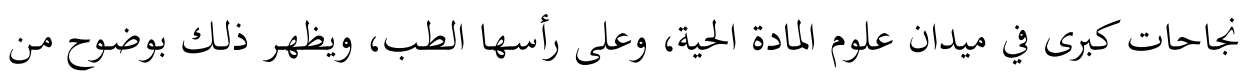
نتائج التكنولوجيا الطبية وتطبيقاتا على الكائن الحي. فبعـد الحـديث في الفلسفة عن مـوت الإله وموت الإنسـان، جـاءت التقنية العلمية

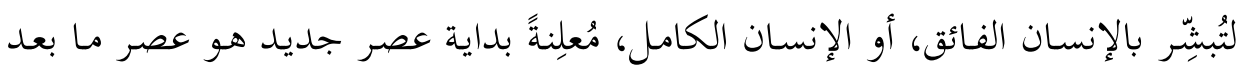

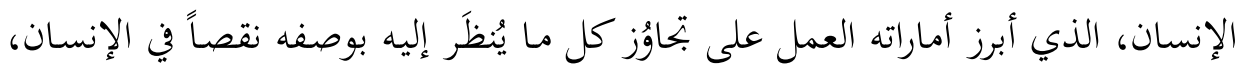

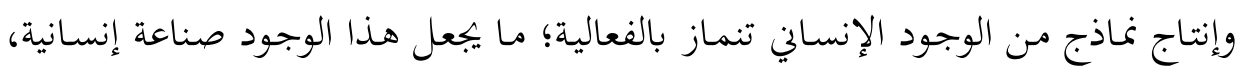




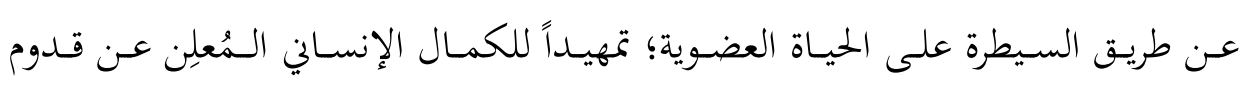
إنسانية جديدة صانعة لمصيرها.

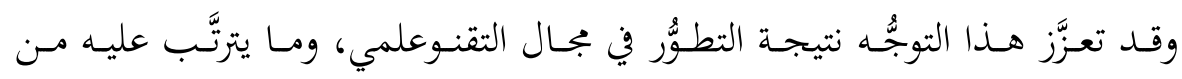

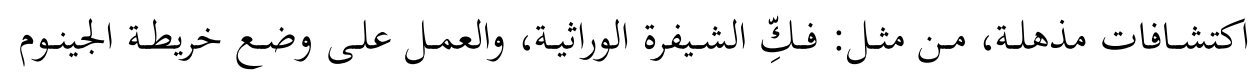

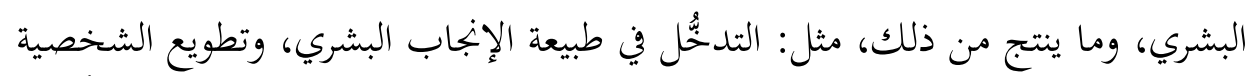

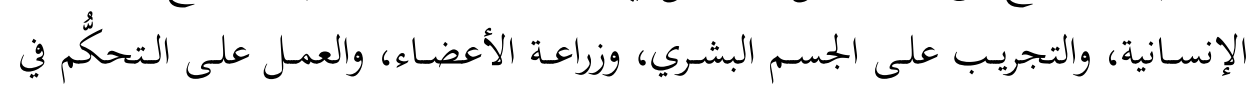

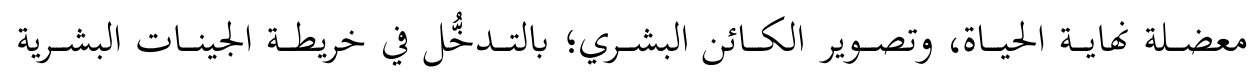

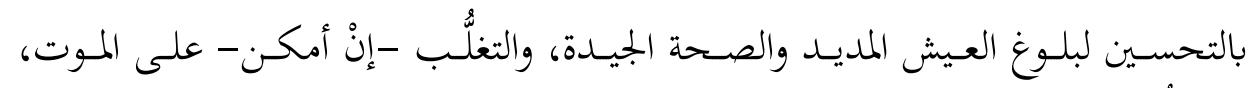
والتمكُّن من إنتاج بشر أقوياء.

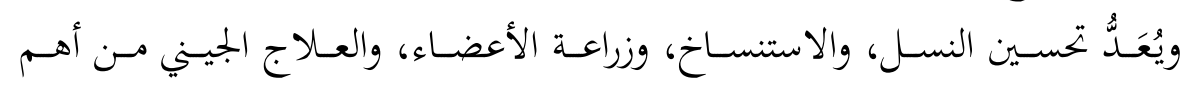

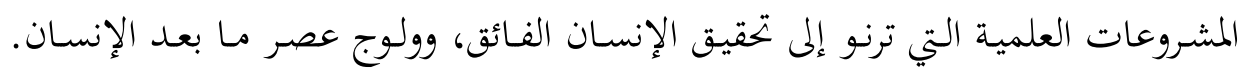

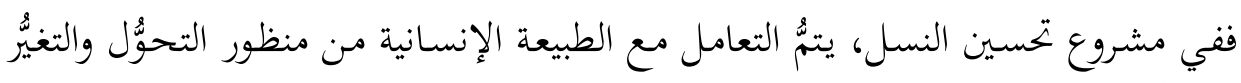

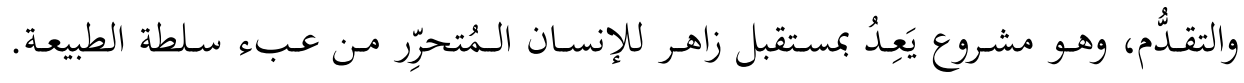

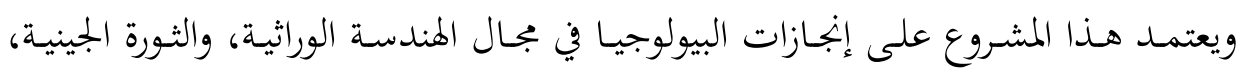

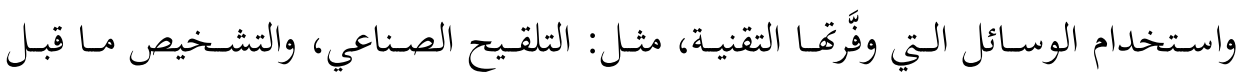

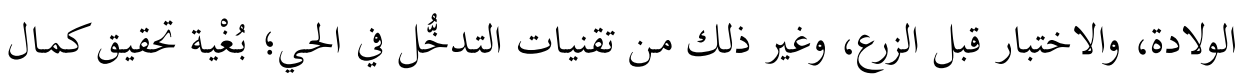

$$
\text { لاحق للحياة الإنسانية. }
$$

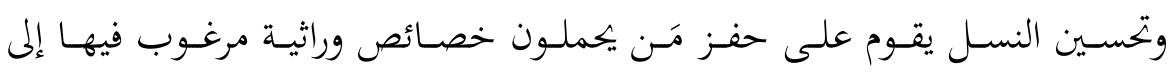

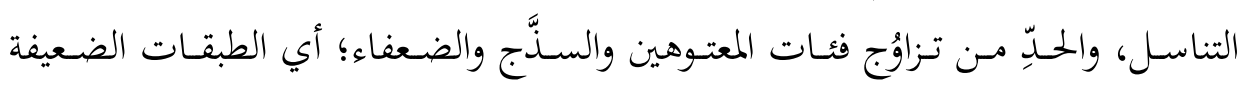

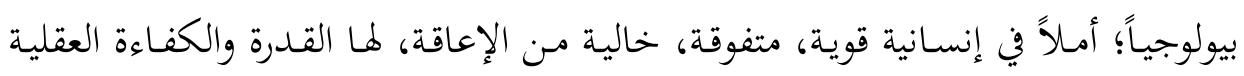

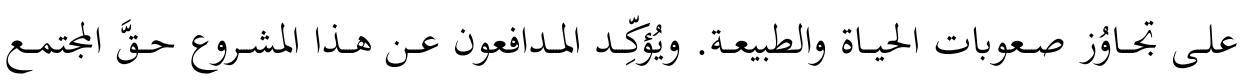

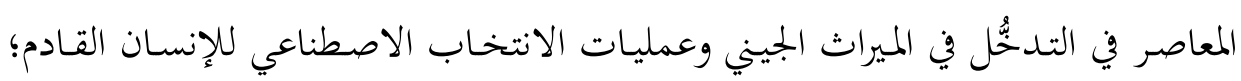

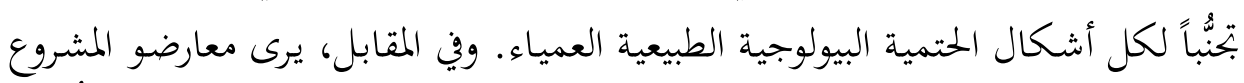

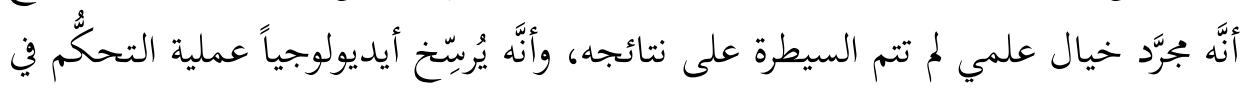

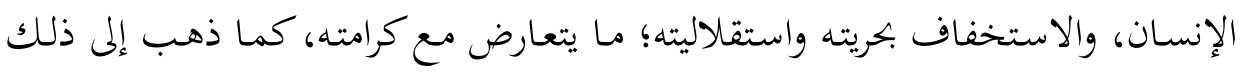


يورغن هابرماس في دفاعه عن الطبيعة الإنسانية، ورفضه تحسين النسل الليبرالي، والتضحية بالاختلاف الذي حفظته الطبيعة على مَرِّ الزمن.

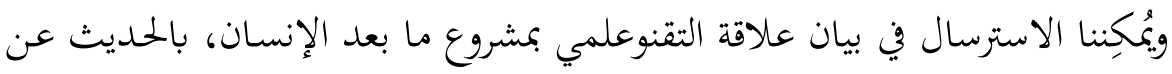

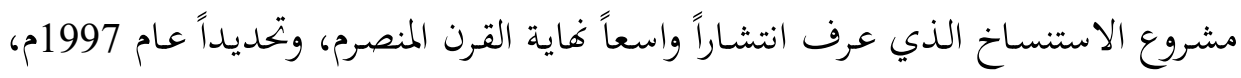
وهو عام الإعلان عن نجاح الاستنساخ الحيواني للنعجة دُوليك؛ ما أفسح المجال للتفكير في وني

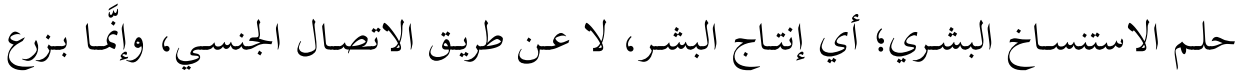

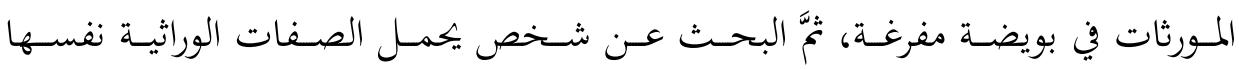

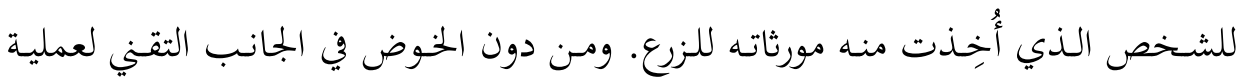

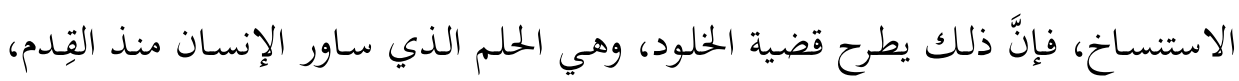

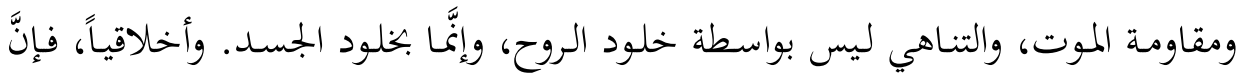

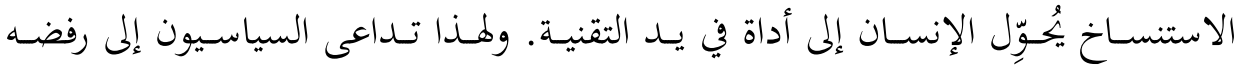

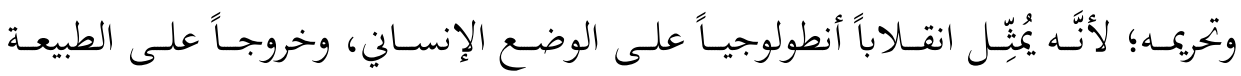

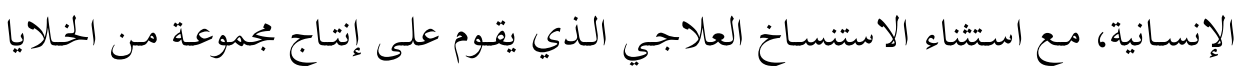

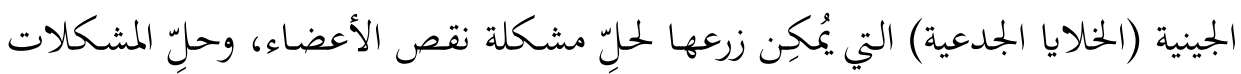
الطبية العويصة. والأمـر لا يتعلَّق بتحســين النسـل والاستنسـاخ فحسبـ، بـل يشـمل كل التقنيـات

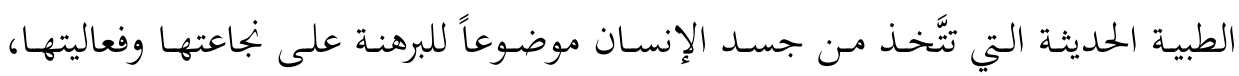

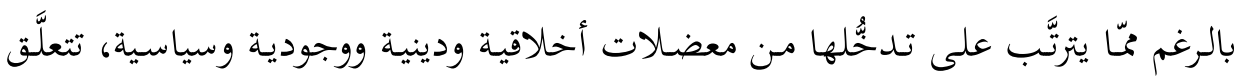
بسؤال الموت والحياة، والخير والشر، والصحة والمرض، والسعادة والشقاء. فهذه التقنيات

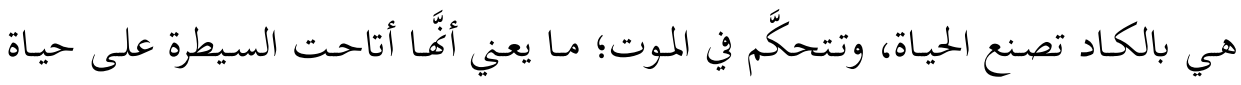

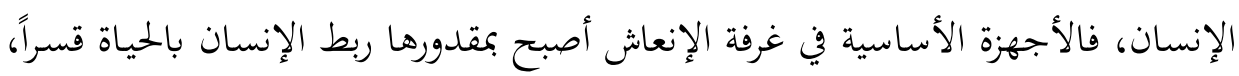

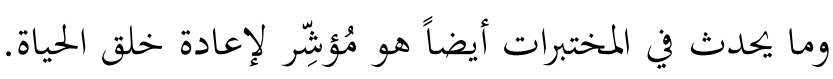

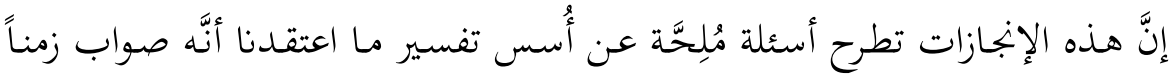

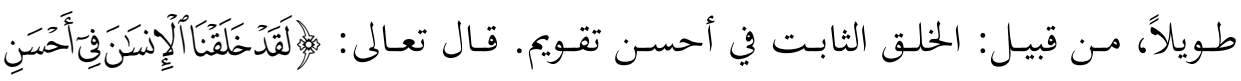

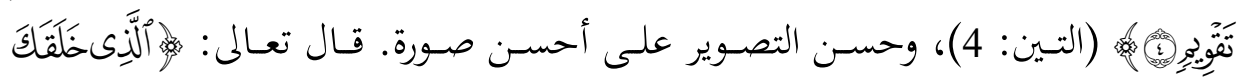




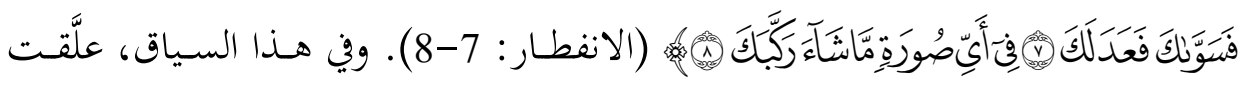

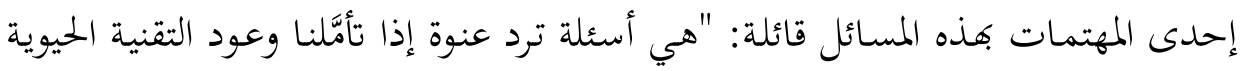

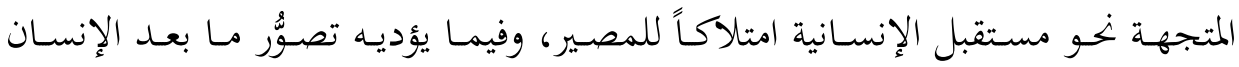

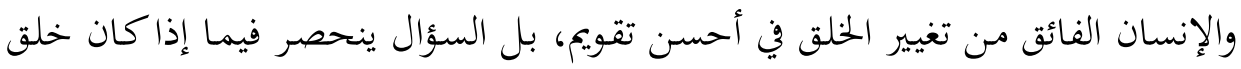

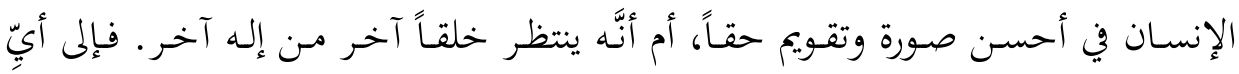

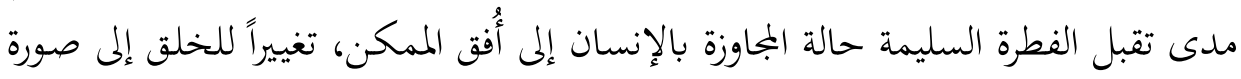

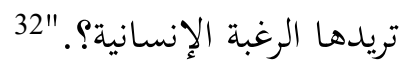

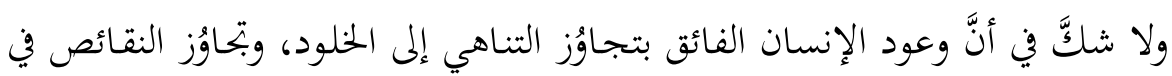

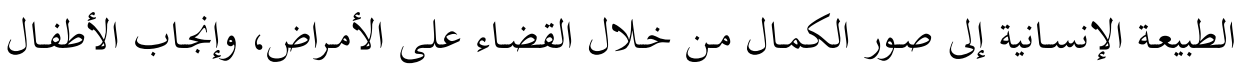

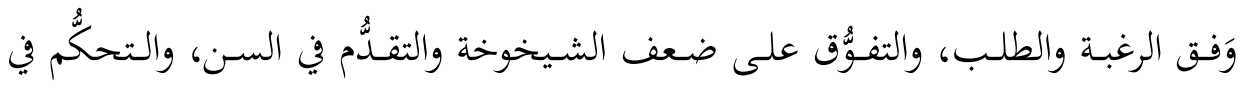

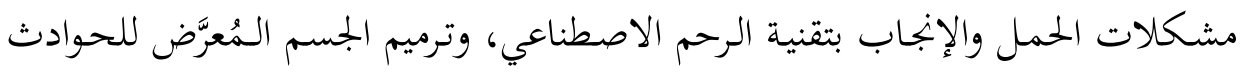

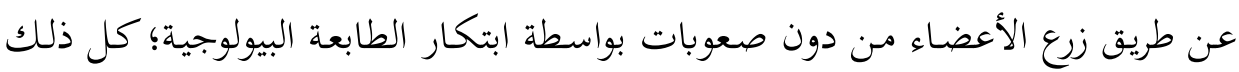

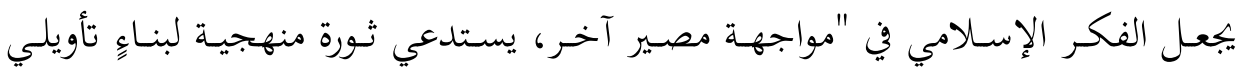

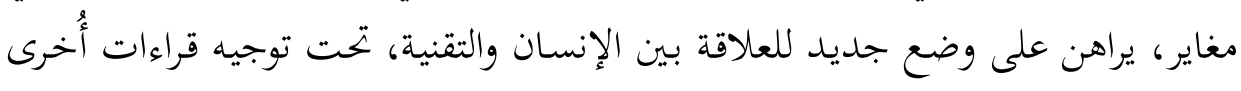

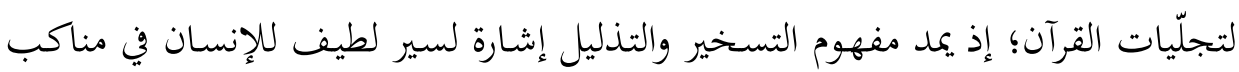

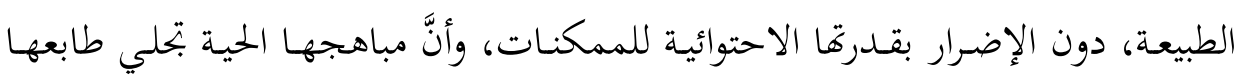

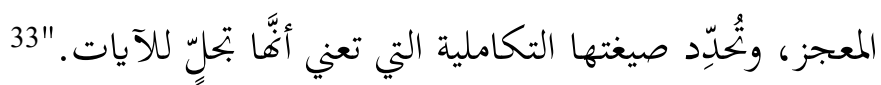

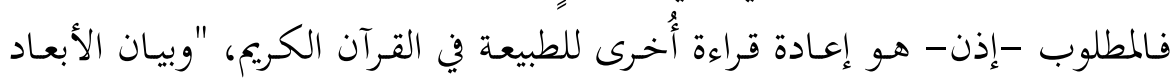

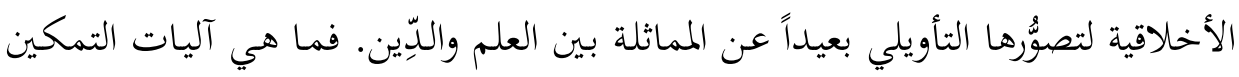

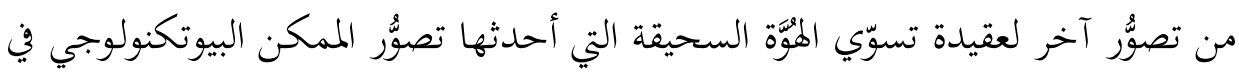

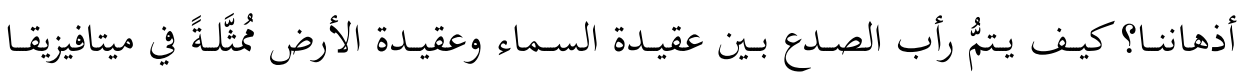
الحمداثة?.

32 بوحناش، نورة. البيوإيتيقا والفلسفة مـ الإنسان الفائق إلى الإنسان المتزكي، بيروت: المؤسسة العربية للفكر

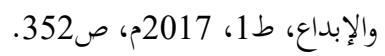
33 33 المرجع السابق، ص353. 34 المرجع السابق، ص354. 


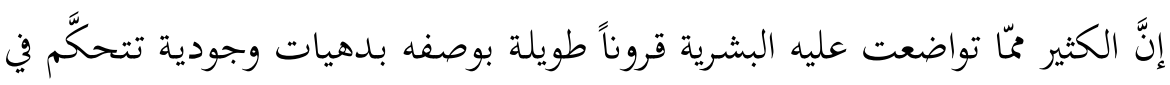
الإنسـان؛ في حياتـه ومماتـه، وي صـحته ومرضـه، وفي خصائصسه البيولوجيـة والنفسـية

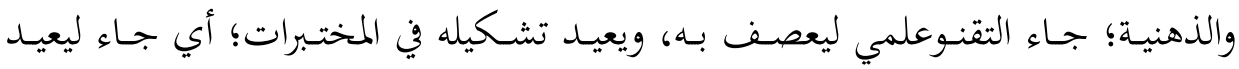

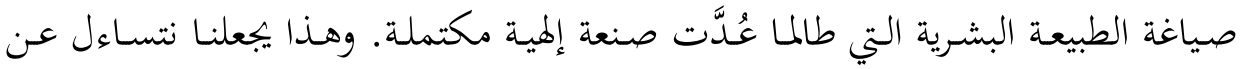

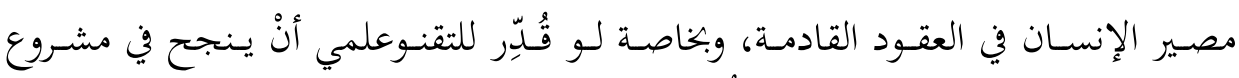

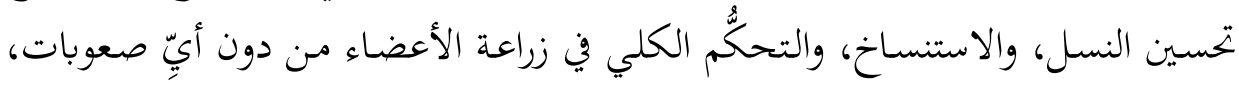

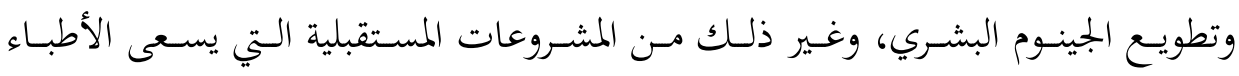
والبيولوجيون إلى تحقيقها.

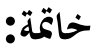

إنَّ التحولات التي عرفها الإنسان عن مفهومه وهويته تعيد طرح مقولة: "الإنسان قد التد

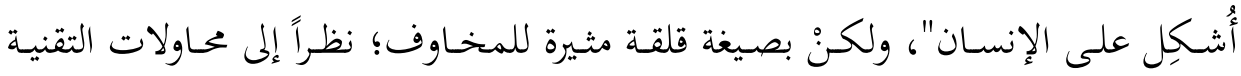

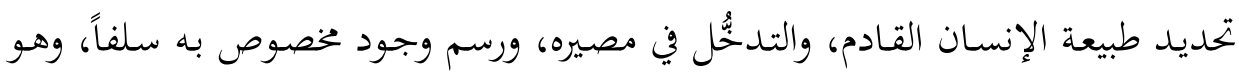

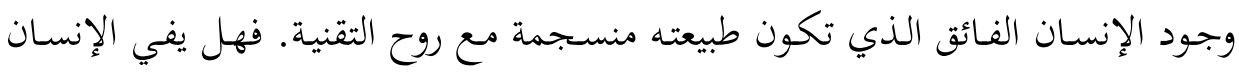
بالغرض على وجهه الصحيح في زمس الاستلاب التكنولوجي، أم سيكون ذلك إلكان إعلاناً عن بداية التدمير الذاتي؟

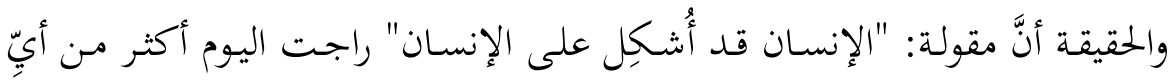

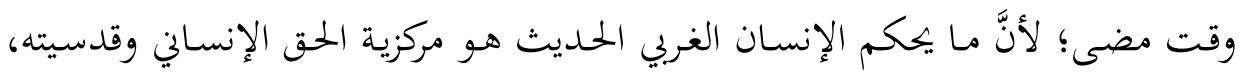

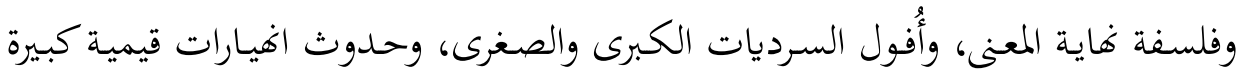

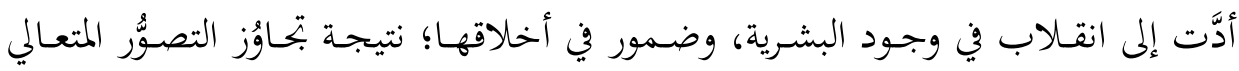

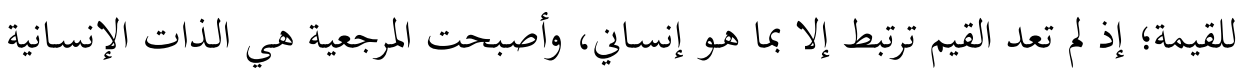
التي وُوسمت بالتأليه والتقديس.

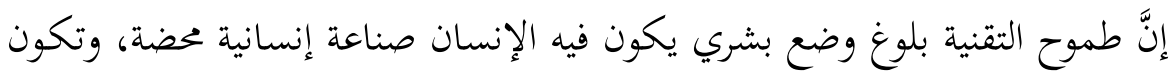

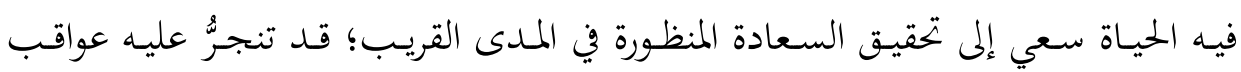

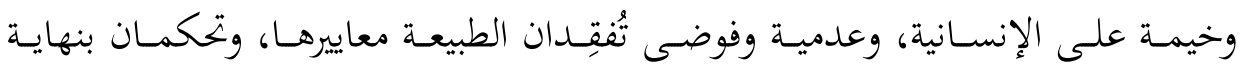


الإنسـان، واقتراب أجلـه، وقـدوم مـا بعـد الإنسـان، أو الإنسـان الفـائق، وهـو الإنسـان إنسان

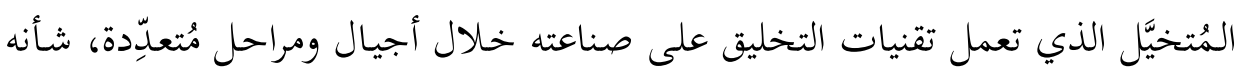
في ذلك شأن الحشرات المتحولة.

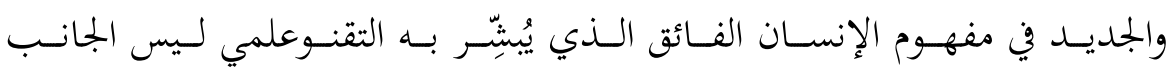

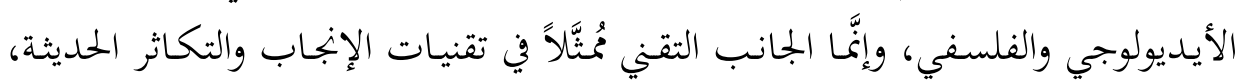

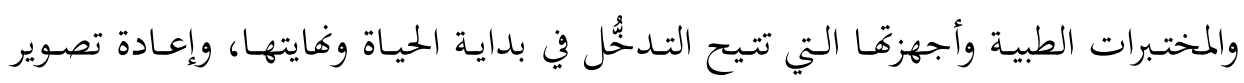

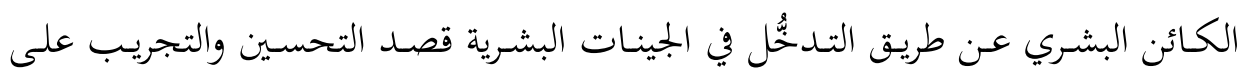

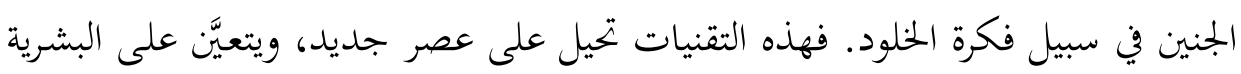

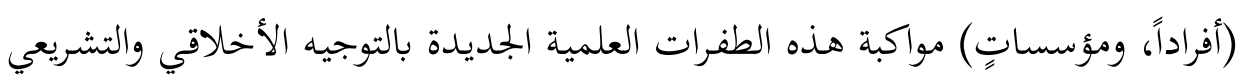
للمحافظة على الطبيعة البشرية ومستقبلها.

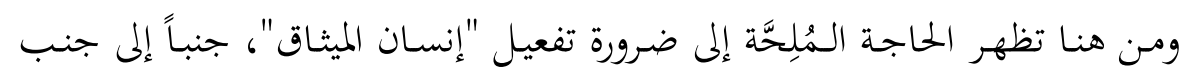

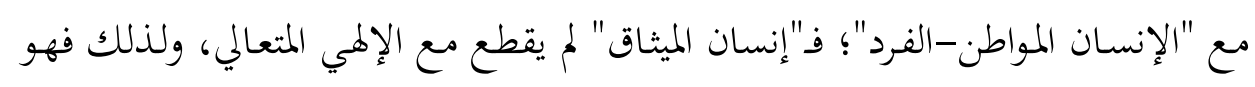

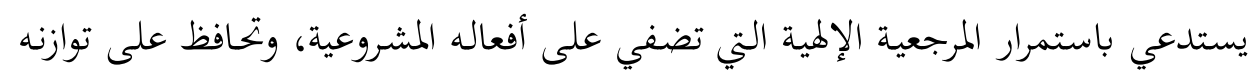

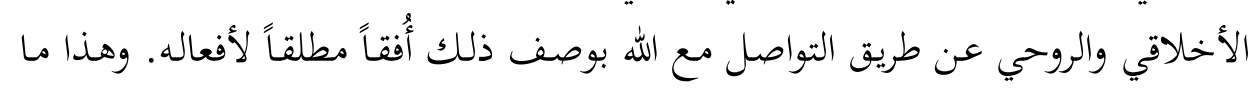

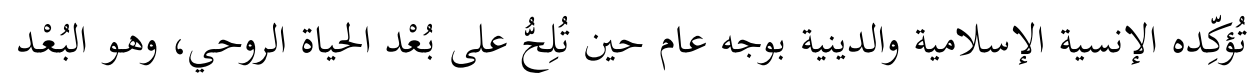

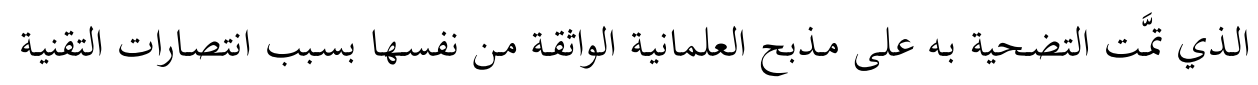
الهائلة. 